\title{
El Sinemuriense superior: cronozonas Obtusum y Oxynotum en Asturias, España. Ammonoideos y correlación con otras cuencas del oeste de Europa
}

\author{
María José COMAS-RENGIFO ${ }^{*}$, Antonio GOY1, Laura PIÑUELA2, José Carlos GARCÍA- \\ RAMOS ${ }^{2}$, Luis Carlos SUÁREZ VEGA ${ }^{2}$ \& Ricardo PAREDES $S^{3}$
}

${ }^{1}$ Departamento de Geodinámica, Estratigrafía y Paleontología, Facultad de Ciencias Geológicas, Universidad Complutense de
Madrid, José Antonio Novais, 12, 28040 Madrid, Spain; mjcomas@ucm.es, angoy@ucm.es
${ }^{2}$ Museo del Jurásico de Asturias (MUJA). Rasa de San Telmo, s/n. San Juan de Duz, 33328 Colunga (Asturias). Spain. lpinuela.
muja@gmail.com; jcgramos.muja@gmail.com
${ }^{3}$ Museu da Ciência. MARE-Marine and Environmental Sciences Centre, Universidade de Coimbra, Portugal: ricardo.paredes@uc.pt

*Corresponding author

Comas-Rengifo, M.J., Goy, A., Piñuela, L., García-Ramos, J.C., Suárez Vega, L.C. \& Paredes, R. 2021. El Sinemuriense superior: cronozonas Obtusum y Oxynotum en Asturias, España. Ammonoideos y correlación con otras cuencas del oeste de Europa. [Upper Sinemurian: Obtusum and Oxynotum chronozones in Asturias, Spain. Ammonoids and correlation with other western European basins]. Spanish Journal of Palaeontology, 36 (1), 19-50.

\section{RESUMEN}

Se estudia la cronoestratigrafía, biosedimentación y, en particular, la sucesión de los ammonoideos que, con un registro relativamente pobre, se encuentra en varias secciones del Sinemuriense superior (cronozonas Obtusum y Oxynotum) de la costa de Asturias, entre la Playa de Peñarrubia (Gijón) y la Playa de Vega (Ribadesella). Si se exceptúa el límite inferior de la cronozona Obtusum, todas las unidades cronoestratigráficas han podido ser caracterizadas con bastante precisión. En la cronozona Obtusum (subcronozonas Obtusum y Stellare) se suceden en el tiempo siete especies de Asteroceras (A. aff. confusum- $A$. confusum- $A$. obtusum- $A$. cf. margaritoides-A. stellare-A. blakei) y Aegasteroceras ( $A$. sagittarium), que de forma puntual pueden estar asociadas a escasos Epophioceras, Xipheroceras, Promicroceras y Cymbites. La subcronozona Denotatus se caracteriza por la sucesión de tres especies de Eparietites (E. undaries-E. impendens-E. glaber) asociadas a raros Promicroceras. En la cronozona Oxynotum se registran Palaeoechioceras, Gagaticeras (G. cf. exortum-G. gagateum) y Oxynoticeras

\begin{abstract}
The chronostratigraphy, biosedimentation and, in particular, the ammonoid succession in several upper Sinemurian sections (Obtusum and Oxynotum chronozones) on the Asturias coast, between Playa de Peñarrubia (Gijón) and Playa de Vega (Ribadesella) are analyzed. With the exception of the lower boundary of the Obtusum chronozone, all chronostratigraphic units have been characterized with relatively good precision. In the Obtusum chronozone (Obtusum and Stellare subchronozones) seven species of Asteroceras followed each other through time ( $A$. aff. confusum- $A$. confusum- $A$. obtusum- $A$. cf. margaritoides- $A$. stellare-A. blakei) and Aegasteroceras (A. sagittarium), locally associated with scarce Epophioceras, Xipheroceras, Promicroceras and Cymbites have been identified. The Denotatus subchronozone is characterized by the vertical succession of three species of Eparietites (E. undaries-E. impendens-E. glaber) associated to rare Promicroceras. In the Oxynotum chronozone, Palaeoechioceras, Gagaticeras (G. cf. exortum-G. gagateum) y Oxynoticeras (O. simpsoni)
\end{abstract}


(O. simpsoni) en la subcronozona Simpsoni y Oxynoticeras (O. oxynotum) asociado a Cheltonia (C. accipitris) en la subcronozona Oxynotum. En la parte media y superior de esta subcronozona, se registran asimismo escasos Paroxynoticeras y escasos Bifericeras y Gleviceras.

En el aspecto paleobiogeográfico, la sucesión obtenida es típica de la Provincia del NO Europeo con la inclusión de algunos elementos más propios de la Provincia Mediterránea en la parte media y superior de la cronozona Obtusum (Asteroceras cf. suevicum, E. glaber) y en la parte media de la cronozona Oxynotum (Paroxynoticeras salisburgense).

Palabras clave: Bioestratigrafía, biosedimentación, correlaciones, Jurásico Inferior, paleobiogeografía. occur in the Simpsoni subchronozone and Oxynoticeras $(O$. oxynotum) is associated with Cheltonia (C. accipitris) in the Oxynotum subchronozone. Scarce Paroxynoticeras, and scarce Bifericeras and Gleviceras occur in the middle and upper parts of this subchronozone, respectively.

From a paleobiogeographic perspective, the recorded ammonite succession is typical of the northwest European Province, albeit having some elements from the Mediterranean Province in the middle and upper parts of the Obtusum chronozone (Asteroceras cf. suevicum, E. glaber) and in the middle part of the Oxynotum chronozone (Paroxynoticeras salisburgense).

Keywords: Biostratigraphy, biosedimentation, correlations, Lower Jurassic, palaeobiogeography.

\section{INTRODUCCIÓN}

La estratigrafía del Sinemuriense (Jurásico Inferior) de la Cordillera Cantábrica ha sido estudiada por numerosos autores desde el siglo XIX. No obstante, existe poca información sobre los ammonoideos de las cronozonas Obtusum y Oxynotum. El registro de este grupo de cefalópodos es escaso y tiene un carácter puntual, por lo que hasta hace pocos años los límites entre las unidades de la zonación estándar permanecían sin precisar.

En este trabajo (1) se estudia la sucesión sedimentaria y la bioestratigrafía de la cronozona Obtusum y de la cronozona Oxynotum, del Sinemuriense superior de la costa asturiana, al E de Gijón; (2) se revisa la Colección Suárez Vega, depositada en el Museo del Jurásico de Asturias (MUJA) en Colunga; y (3) se completa la información con estudios detallados en varias secciones locales como las de la Playa de Peñarrubia (PÑ) (Gijón), Punta de Rodiles E (ER), Punta de la Llastra O (LLO), Huerres (HU) y Playa de Vega (PV), asi como en otros afloramientos intermedios, como El Puntal (PU), Playa de Rodiles O (OR) y Villar (VI) (Fig. 1).

\section{ANTECEDENTES HISTÓRICOS}

Desde la segunda mitad del siglo XIX, autores como Schulz (1858), Mallada $(1885,1902)$ y Jiménez de Cisneros (1904) se refieren a la existencia de ammonoideos del Sinemuriense, en ocasiones de gran tamaño, como Ammonites bisulcatus Bruguière, Ammonites planicosta Sowerby y Arietites. Dubar (1925a, 1925b) estudia los afloramientos del Jurásico Inferior situados al E de Gijón y en Ribadesella, citando Asteroceras stellare (Sowerby) y Oxynoticeras entre Gijón y el Cabo de San Lorenzo. Por su parte Dubar \& Mouterde (1957) hacen referencia a un nivel con Promicroceras sp., asociados a Zeilleria perforata (Piette) y Entolium hehli (d'Orbigny), en la playa de Rodiles y a la existencia de Asteroceras sp., seguido, a cierta distancia estratigráfica, por Arnioceras cf. ceratitoides (Quenstedt), Zeilleria perforata y Entolium hehli en la bahía situada al E de la punta de Rodiles. Dubar et al. (1971) esbozan las líneas generales de la estratigrafía del Jurásico de Asturias y caracterizan la cronozona Obtusum por la presencia de Asteroceras stellare (Sowerby), Asteroceras sp., Promicroceras sp. y Arnioceras cf. ceratitoides (Quenstedt) y la cronozona Oxynotum por Oxynoticeras oxynotum (Quenstedt), Oxynoticeras sp. y $O$. cf. cluniacense (Dumortier).

Suárez Vega (1974) estudia por primera vez, de forma detallada, las secciones del Sinemuriense superior de PÑ, ER y PV, así como algunos afloramientos del interior como los de Cimero (al E de La Collada), Argañoso, La Vega de Sariego, etc., que proporcionaron varios ejemplares de Asteroceras y Oxynoticeras. En conjunto, caracteriza la zona Obtusum, con un horizonte de Obtusum en la parte inferior, en la que distingue de base a techo: Asteroceras gr. obtusum? (Sow.), Asteroceras confusum Spath y Asteroceras sps.; Caenisites cf. turneri? (Sow.); Asteroceras cf. stellare (Sow.), y Asteroceras sps.; Asteroceras suevicum? (Qu-). En la zona Oxynotum distingue Oxynoticeras gr. oxynotum (Quenstedt).

Entre los años 1985 y 2004, Valenzuela et al. (1985, 1986, 1989), García-Ramos et al. (1989, 1992), GarcíaRamos \& Gutiérrez-Claverol (1995a, 1995b), Meléndez et al. (2002), Aurell et al. (2003) y Robles et al. (2004) estudian la geología sedimentaria del Jurásico marino de la costa asturiana y definen las unidades litoestratigráficas y secuenciales del sector estudiado. Unos años después, García-Ramos et al. (2010) realizan una introducción al Jurásico de Asturias, Comas-Rengifo \& Goy (2010) y Bádenas et al. (2010a, 2010b) estudian, respectivamente, la biocronoestratigrafía y los ciclos sedimentarios del Sinemuriense superior en los acantilados de PV y Comas-Rengifo et al. (2010) caracterizan, en la sección 

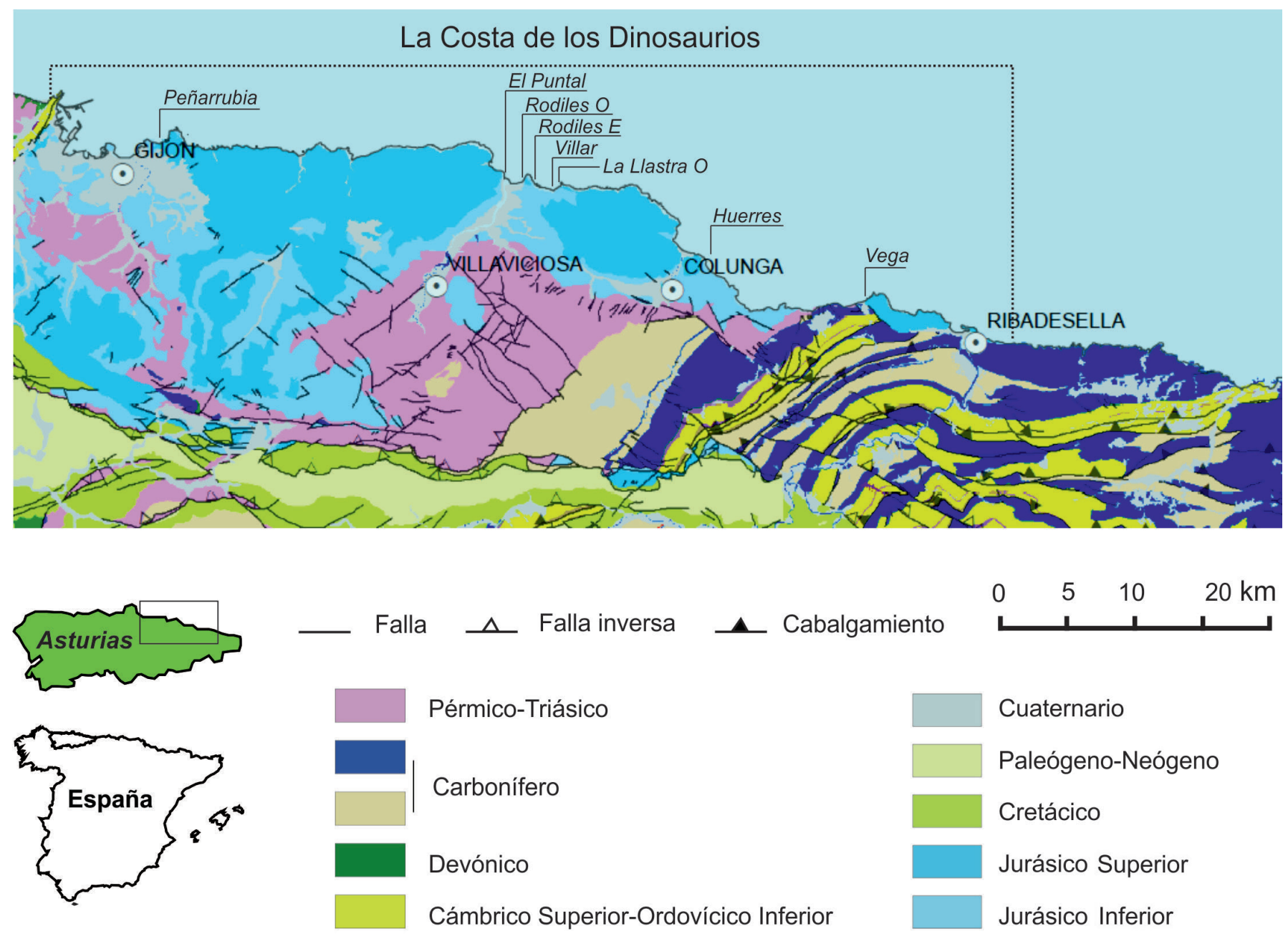

Figura 1. Mapa de los afloramientos del Jurásico Inferior en Asturias y situación de las secciones y localidades estudiadas: sección de la Playa de Peñarrubia, sección de la Punta de Rodiles E, sección de la Punta de la Llastra O, sección de Huerres, sección de la Playa de Vega. Otras localidades: El Puntal, Villar.

de ER la cronozona Obtusum (subcronozona Stellare) por la presencia de Asteroceras cf. stellare (Sowerby) y Asteroceras blakei (Spath), situando el límite inferior de la cronozona Oxynotum con el primer registro de Gagaticeras gagateum (Spath). Por último, GarcíaRamos et al. (2011) realizan un estudio icnológico y de estratigrafía secuencial del Sinemuriense superior en las localidades de VI y PU (Villaviciosa).

\section{SUCESIÓN ESTRATIGRÁFICA}

\subsection{Litoestratigrafía y biofacies}

Las rocas carbonáticas del intervalo Sinemuriense superior (cronozona Obtusum-cronozona Oxynotum), en la costa centro-oriental asturiana, pertenecen a la Formación (Fm.) Rodiles, Miembro (Mb.) Buerres (Valenzuela et al.,
1986) (Fig. 2) y su sedimentación tuvo lugar en un mar epicontinental de fondo irregular con umbrales y depocentros, a una profundidad comprendida entre ligeramente por debajo del nivel de base del oleaje de tempestad y por encima del nivel de base del oleaje de buen tiempo como se deduce por las estructuras sedimentarias (ripples de oleaje, estratificación cruzada hummocky, etc) y su posición dentro de cada secuencia. Aunque no se aprecian indicios de emersión, los términos más someros se sitúan en la parte basal, donde se han encontrado colonias de corales (Fig. 2f) y bivalvos del género Antiquilima y se observan, al menos, dos intercalaciones de materiales siliciclásticos (Fig. 2a). Además, se reconocen aquí, ligeramente por debajo del primer nivel siliciclástico, algunos niveles estromatolíticos asociados a zonas intermareales. En torno al tránsito a la cronozona Oxynotum se produce una profundización generalizada reconocible, sobre todo, en las secciones más expandidas, PÑ, ER y LLO, tal como indica el incremento en la proporción marga/caliza, la mayor continuidad lateral 

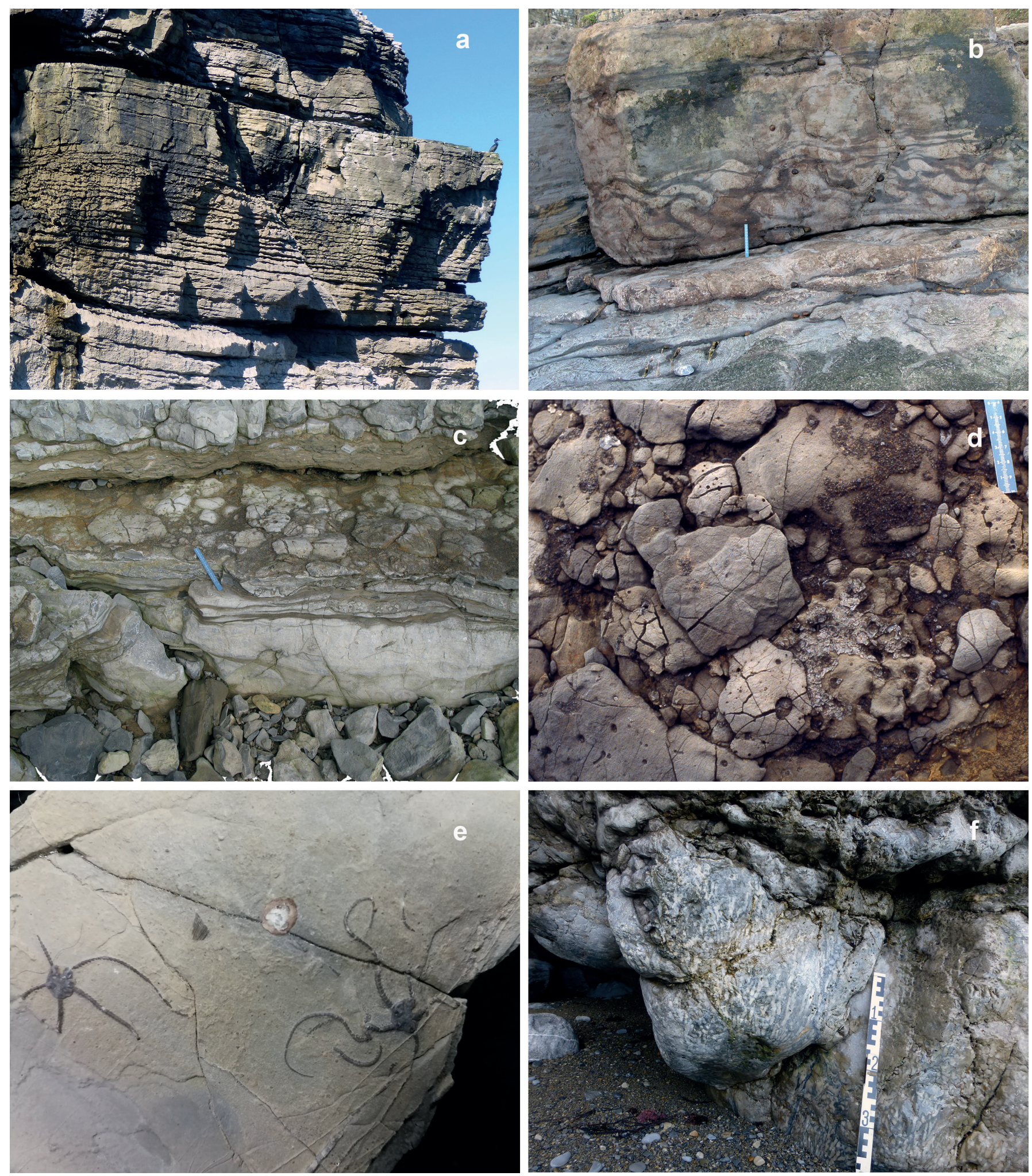

Figura 2. Parte inferior de la Fm. Rodiles (Mb. Buerres) correspondiente a la cronozona Obtusum (subcronozonas Obtusum y Stellare). a) Niveles con terrígenos, PÑ. b) Nivel de Convolute beds C4 (subcronozona Obtusum), PÑ. c-d) Hardground removilizado con perforaciones de bivalvos (Gastrochaenolites) y de gusanos (Trypanites), ostreidos incrustantes y rellenos bioclásticos. Techo del nivel de Convolute beds C2 (subcronozona Obtusum), VI. e) Ofiuroideos (subcronozona Obtusum), LLO. f) Corales coloniales, PÑ. 
de las capas que constituyen dichas alternancias y la mayor regularidad de las superficies de contacto entre ambas ya que se adaptan parcialmente a las estructuras primarias previas a la diagénesis. El espesor de la sucesión aumenta progresivamente de $\mathrm{E}$ a $\mathrm{O}$ con valores mínimos en $\mathrm{PV}$ (aproximadamente 14,5 m para la cronozona Obtusum y $9 \mathrm{~m}$ para la cronozona Oxynotum) y máximos en PÑ (al menos de $25 \mathrm{~m}$ para Obtusum y más de $24 \mathrm{~m}$ para Oxynotum). Los valores son aproximados porque el límite inferior de la cronozona Obtusum y el superior de la cronozona Oxynotum no se pueden situar con precisión.

El conjunto está constituido por alternancias de calizas y margas grises que se ordenan en secuencias asimétricas transgresivo-regresivas con espesores variables (0,4-3 m). La asimetría de las mismas se traduce en un mayor espesor relativo de la tendencia regresiva respecto a la transgresiva; no obstante, la desigualdad actual entre ambas tendencias está acentuada porque el tramo transgresivo suele tener una mayor proporción de margas por lo que ha sufrido más compactación, dado que la precipitación de carbonato cálcico en las calizas tuvo lugar en una etapa diagénetica muy temprana. Los límites de las secuencias representan superficies de omisión y erosión de tipo firmground o hardground (Figs. 2c-d), dependiendo respectivamente de la mayor o menor batimetría de su origen.

La secuencia ideal comienza por alternancias de calizas wackestone a mudstone y margas más o menos bioclásticas en capas plano-paralelas, a menudo con Rhizocorallium (Figs. 3a-b) verticalizados, Diplocraterion, Chondrites (Figs. 3b-c) y algunos Arenicolites, Kulindrichnus y Conichnus (Fig. 3d), que pasan hacia arriba a términos nodulosos en los que se incrementa cada vez más la proporción caliza/marga hasta pasar superiormente a una caliza amalgamada wackestone a packestone que culmina en un firmground o en un hardground dependiendo de la menor o mayor energía a que esté sometido el fondo. En las superficies de máxima inundación pueden aparecer concentraciones de ejemplares de Zeilleria. En los términos nodulosos de la parte intermedia regresiva son frecuentes los bivalvos infaunales profundos (Pholadomya, Pleuromya, Gresslya) en posición de vida. En las calizas superiores muy bioclásticas se encuentran pínnidos, muchos de ellos también en posición de vida mostrando estructuras bioturbadas subyacentes de escape, así como frecuentes gasterópodos (Pseudomelania), que llegan a alcanzar grandes tallas. Los hardgrounds (Figs. 2c-d), situados a techo de algunas de las secuencias originadas en ambientes más someros y energéticos, muestran episodios de removilización erosiva que liberan clastos calcáreos intraformacionales. En estos hardgrounds son frecuentes los ostreidos incrustantes y diversas evidencias de actividad de organismos que viven en fondos firmes representadas por trazas de Thalassinoides (Fig. 3f) y Diplocraterion, así como perforaciones de gusanos y bivalvos (Trypanites y Gastrochaenolites, respectivamente) (Fig. 2d). Estos últimos aparecen, a menudo, truncados por la erosión en la parte superior. Otros icnofósiles presentes son Planolites (Fig. 3b), Palaeophycus, Curvolithus (Fig. 3e) y Teichichnus. Para mayor detalle del origen y estructura de estas secuencias ver Valenzuela et al. (1985, 1986, 1989) y García-Ramos et al. (1992), aunque en dichos artículos figuran como parasecuencias, debido a que aún no se había reconocido en ellos el pequeño intervalo transgresivo representado en las bases de las mismas.

En la sucesión destacan cuatro niveles característicos (C1 a C4) de alternancias irregulares de margas y calizas pelletoidales granosoportadas, pobres en fósiles, que muestran estructuras de deformación sinsedimentaria como convolute beddings (Fig. 2b) y slumps. Los pellets fueron transportados hasta aquí probablemente desde áreas más someras de tipo lagoon durante episodios súbitos ricos en fango de descargas de tormentas desde el continente y asociadas a tempestades (las pelmicritas muestran a menudo estratificación cruzada hummocky y el conjunto tiene una base canalizada). Estos cuatro intervalos pertenecen a la subcronozona Obtusum y representan niveles guía correlacionables en la mayor parte de las secciones costeras, especialmente el segundo más inferior que es el más destacado en todas ellas. El tercero contiene un nivel rico en ofiuroideos (Fig. 2e). Su origen estuvo relacionado probablemente con episodios generados por corrientes de reflujo de tempestad (storm surge ebb), aunque no puede descartarse una relación de las mismas con sacudidas sísmicas. Una interpretación alternativa, aunque en parte relacionada con la anterior, que ayudaría a explicar la escasez de macrofauna bentónica característica de estos tres episodios, es que se trate de rellenos de canales intra-plataforma generados por procesos relacionados con grandes avenidas fluviales en el continente asociadas a tempestades intensas (intra-shelf storm-flood channel deposits). Esta última interpretación se basa fundamentalmente en observaciones de campo: las estructuras de deformación muestran siempre bases canalizadas, su composición es la de pelmicritas, carecen de cuerpos fósiles y de icnofauna y muestran internamente estratificación cruzada de tipo hummocky.

El origen de las secuencias transgresivo-regresivas probablemente estuvo relacionado con impulsos intermitentes y rápidos de subsidencia tectónica asociados al rejuego de fallas extensivas más profundas. Estas se propagaron superiormente en pliegues laxos (deformación flexural) al alcanzar los niveles de evaporitas del Rhetiense-Hettangiense que, gracias a su comportamiento dúctil, sirvieron de amortiguación de las mismas. La disolución parcial y/o el desplazamiento lateral de las masas evaporíticas como consecuencia de la carga sedimentaria del rejuego de las fallas pudo contribuir a estos procesos de subsidencia a impulsos. Estos últimos generaron sucesivos espacios de acomodación que se van reduciendo luego progresivamente a medida que la tasa de nuevos aportes sedimentarios 

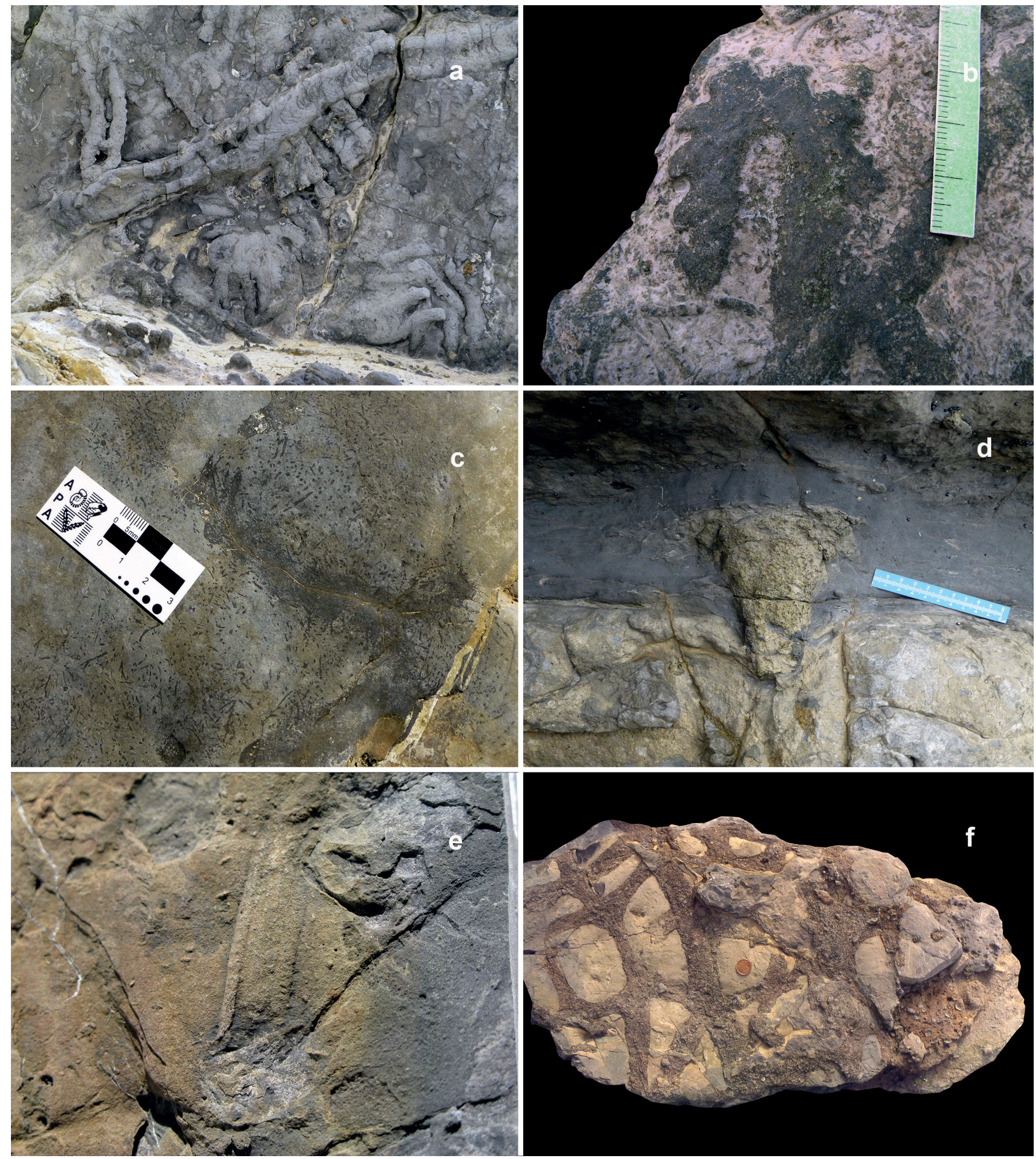

Figura 3. Icnofósiles frecuentes en las secciones estudiadas. a) Rhizocorallium sp., cronozona Oxynotum, ER. b) Rhizocorallium jenense spinosus Rodríguez-Tovar et al., 2012, Chondrites sp. y Planolites sp., subcronozona Obtusum, PU. c) Chondrites sp., subcronozona Obtusum, PÑ. d) Conichnus sp., cronozona Oxynotum, HU. e) Curvolithus sp., subcronozona Obtusum. HU, f) Galerías de crustáceos decápodos (Thalassinoides suevicus Rieth, 1932) con relleno bioclástico en la superficie de un hardground, subcronozona Obtusum, VI. 
compensa la subsidencia; está última se irá ralentizando gradualmente hasta la llegada de un nuevo episodio súbito de hundimiento. De los cuatro posibles orígenes de las secuencias (tectónico, climático, eustático y autocíclico) nos inclinamos por el primero de ellos por varias razones. La acusada irregularidad en el tamaño, estructura interna y ordenamiento vertical de las mismas sugiere descartar un origen climático. La asusencia de referencias sobre ciclos de tan alta resolución bien datados no permite aún realizar comparaciones para verificar un posible origen eustático. Por otra parte, el carácter sublitoral de las secuencias descartaría un origen autocíclico. Bosence et al. (2009) y Bádenas et al. (2010a) han atribuido también a procesos tectónicos locales o regionales secuencias similares a estas en el Sinemuriense del borde occidental del Tetis.

Por otro lado, el espesor relativamente elevado de las cronozonas Obtusum y Oxynotum en los afloramientos más occidentales, que llega en este caso a duplicar el de los afloramientos más orientales, confirma la acusada subsidencia local y su carácter diferencial en distancias relativamente cortas ( $41 \mathrm{~km}$ entre PV y PÑ), lo que apunta a procesos tectónicos sinsedimentarios de cierta intensidad durante esta época. El contexto se enmarca a su vez en una fase extensional (rifting) menor asociada a un límite de placa abortado y relacionada con el desplazamiento lateral hacia el E de la Placa Africana que contribuye a la apertura del Atlántico Central (Vegas et al., 2016).

Dentro de un ámbito paleogeográfico más amplio, esta sucesión es relativamente más profunda que algunas de las equivalentes en edad, como las de Almonacid de la Cuba en la Cordillera Ibérica, la de Alfara en la Cordillera Costero-Catalana, las de los Pirineos centrales o de Mallorca, pero menos que las de la costa de Dorset en el sur de Inglaterra o la de San Pedro de Moel (Portugal).

\subsection{Límites de secuencias en las secciones de la Cuenca Asturiana}

La base de la cronozona Obtusum, aunque no es reconocible aún en Asturias con precisión debido a la ausencia de registro de ammonites, debería situarse en torno al nivel rico en siliciclásticos (calizas arenosas con estratificación cruzada). Dicho nivel ha sido identificado en todos los afloramientos mencionados e incluido en la columna de Peñarrubia y coincidiría con un límite de secuencia deposicional de segundo orden reconocible en buena parte de la Cuenca Central Europea (Haq et al., 1988; De Graciansky et al., 1998; Hesselbo \& Jenkyns, 1998; Gómez \& Goy, 2005; Quesada et al., 2005; Barth et al., 2018).

En cuanto al límite entre las cronozonas Obtusum y Oxynotum, coincide con una superficie de máxima inundación dentro de un ciclo de segundo orden en las cuencas del Mar del Norte así como en las del Reino Unido, como en el Yorkshire y oeste de Escocia (Cuenca de Hébridas), a excepción de Dorset, donde la correlación es problemática debido a la presencia allí de un hiato erosivo que abarca la parte más superior de la cronozona Obtusum y la totalidad de la cronozona Oxynotum (Haq et al., 1988; Hesselbo \& Jenkyns, 1998; Hesselbo, 2008). Según Barth et al. (2018) en diversas subcuencas dentro de la Cuenca Central Europea, como las de Inglaterra, Cuenca de París Occidental, Cuenca de Alemania septentrional y Cuenca de Polonia, esta superficie de máxima inundación es reconocible igualmente.

Sin embargo, en la Cuenca Asturiana el límite entre ambas cronozonas se sitúa ligeramente por encima del inicio del intervalo transgresivo de una secuencia y bastante por debajo de la superficie de máxima inundación de la misma. Esta diferencia con respecto a las subcuencas europeas antes mencionadas se debe probablemente a la influencia de fenómenos tectónicos de índole local o regional superpuestos a los de carácter eustático.

\subsection{Secciones y sucesión bioestratigráfica}

En el área investigada, solo en la parte oriental (sección PV), se aprecian algunas discontinuidades significativas. Las restantes secciones son relativamente expandidas, con una sucesión de ammonoideos que permite caracterizar las subcronozonas Obtusum, Stellare y Denotatus de la cronozona Obtusum y las subcronozonas Simpsoni y Oxynotum de la cronozona Oxynotum. En ningún caso se han apreciado discontinuidades que tengan un rango mayor de una subcronozona.

La distribución de los ammonoideos registrados en PÑ, ER y PV puede verse en las Figuras 4-6. La sección más completa y representativa es la de PÑ donde, con más o menos precisión, se han podido caracterizar todas las unidades cronoestratigráficas reconocidas en la costa asturiana. La sección ER es importante para el intervalo comprendido entre la parte superior de la subcronozona Stellare y la subcronozona Oxynotum. En las secciones LLO y HU afloran bien los sedimentos carbonáticos de la parte inferior de la cronozona Obtusum. En ambos casos, por encima de niveles con materiales terrígenos, similares a los que se encuentran en PÑ (Fig. 4; "tramo c"), destaca la presencia de Epophioceras del grupo de E. longicella (Quenstedt) en un nivel equivalente al techo del "tramo e", que está seguido de varios niveles con Asteroceras aff. confusum Spath, como también ocurre en PÑ (Fig. 4; "tramos j y k"). Todos ellos se sitúan por debajo del segundo nivel con convolute beds (C2). Por otra parte, cerca de LLO, en Villar, se ha encontrado ex situ un ejemplar de Epophioceras cf. landrioti (d'Orbigny) que procede probablemente de niveles de la subcronozona Stellare, más antiguos que los que contienen A. blakei.

Por último, en la sección PV son evidentes algunas discontinuidades importantes, como la situada en el 


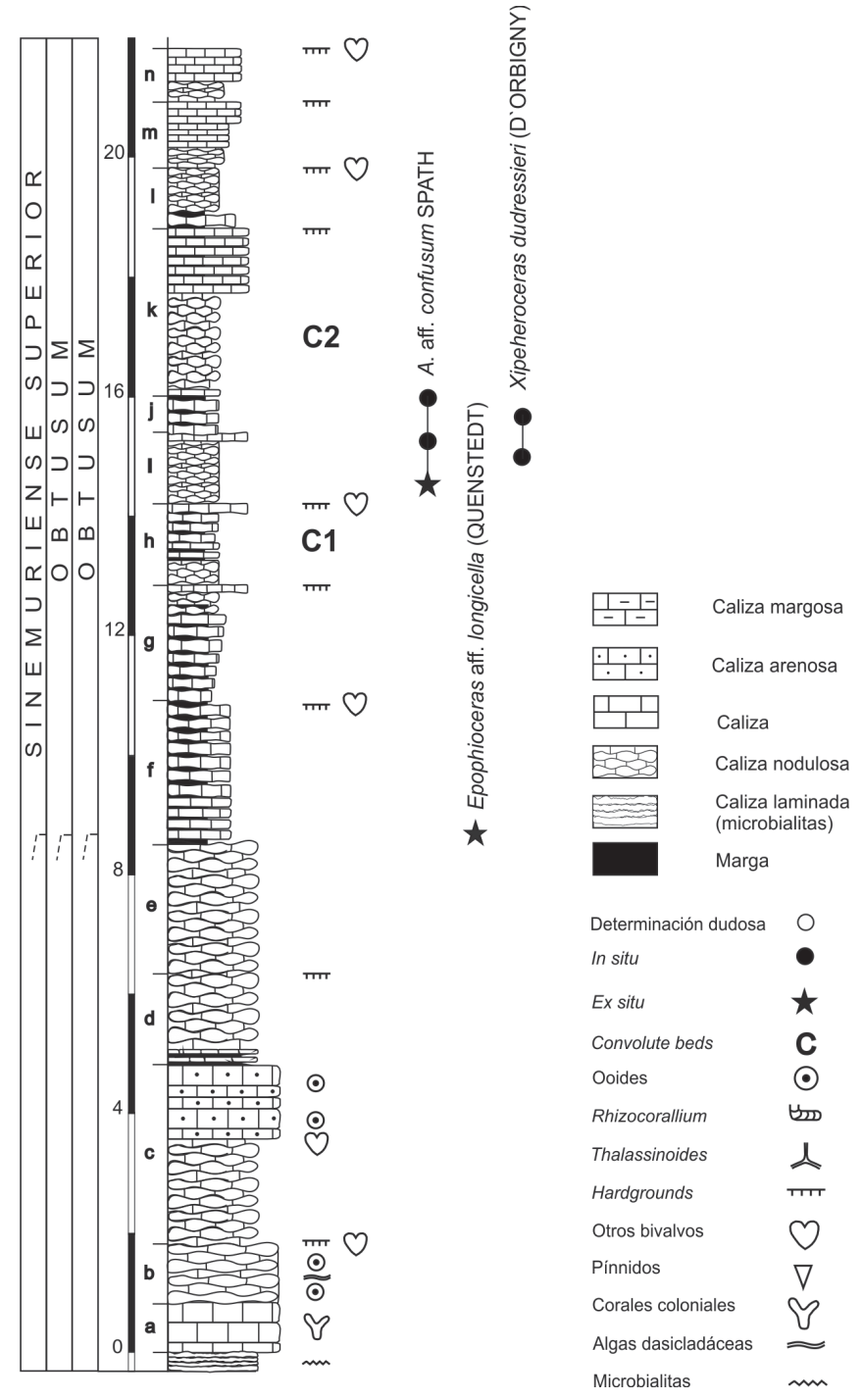

Figura 4. Distribución de los ammonoideos en la sección de Peñarrubia 1.

tránsito entre la subcronozona Denotatus y la subcronozona Oxynotum (Fig. 6). Aquí son frecuentes los braquiópodos (Comas-Rengifo \& Goy, 2010) y son escasos los ammonoideos del intervalo comprendido entre la parte terminal de la subcronozona Stellare y la subcronozona Oxynotum.

El registro de los ammonoideos en los materiales estudiados es escaso y muchas veces discontinuo. En general, la preservación no es buena y casi siempre el relleno de las conchas es similar a la matriz donde se conservan, por lo que suelen estar deformados y, rara vez, se han podido obtener completos. No obstante, son raros los ejemplares donde se aprecia que hay evidencias de reelaboración, como ocurre, por ejemplo, en el tránsito entre los niveles 31 y 32 de PV, coincidiendo con una discontinuidad cuya amplitud es difícil de evaluar con precisión.

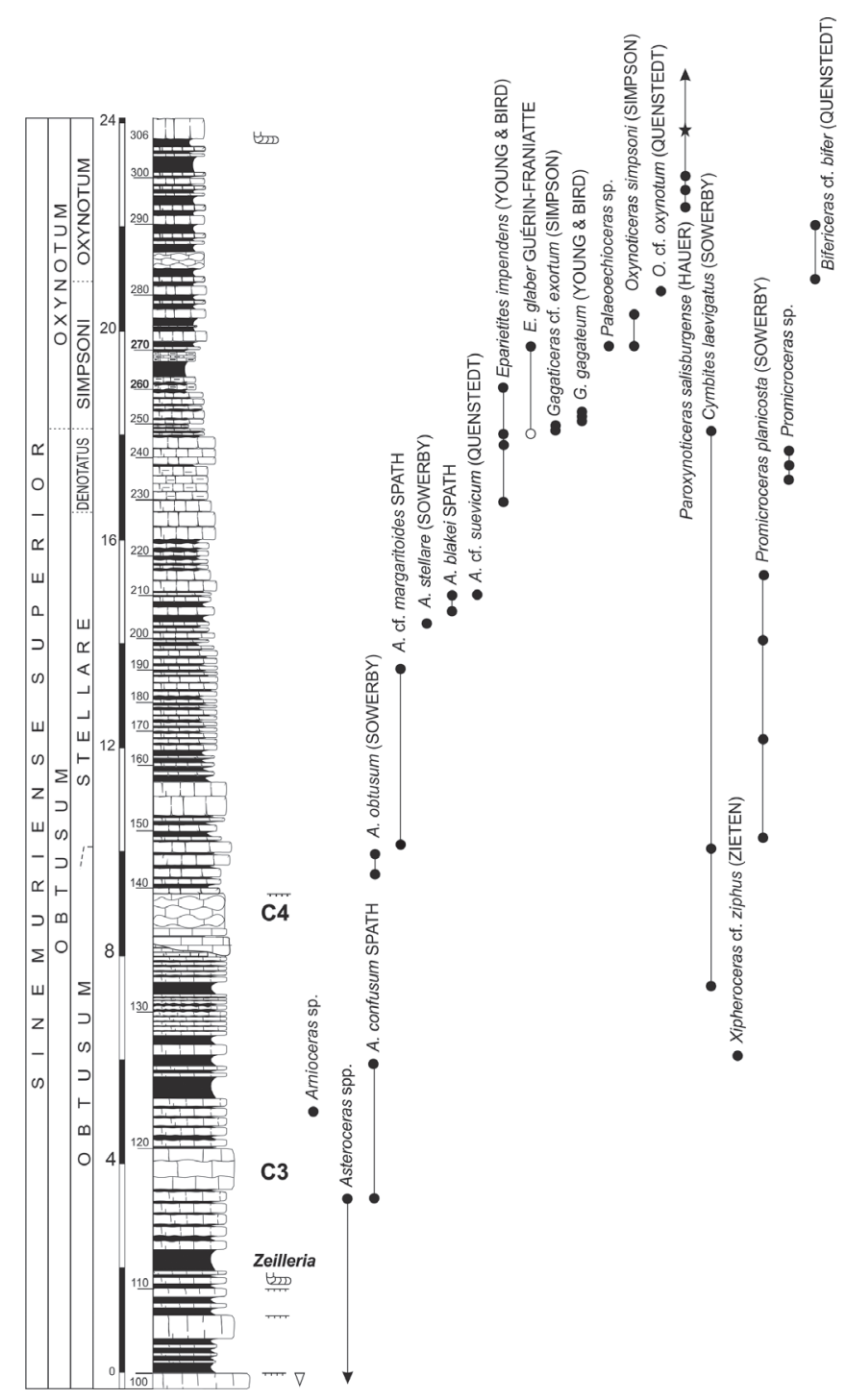

Figura 5. Distribución de los ammonoideos en la sección de Peñarrubia2.

\section{MATERIAL Y MÉTODOS}

Para la realización de este trabajo se han estudiado los ammonoideos recogidos por Suárez Vega (1974) durante la realización de su Tesis Doctoral, que están depositados en el Museo del Jurásico de Asturias (MUJA), así como algunos especímenes recogidos por Dubar \& Mouterde (1957) que forman parte de las colecciones del MUJA y los que bajo la denominación de "Colección Mouterde" están depositados en el Área de Paleontología del Departamento de Geodinámica, Estratigrafía y Paleontología de la Universidad Complutense de Madrid.

Por otra parte, desde el año 2012 se procedió al levantamiento pormenorizado de las secciones PÑ1 y PÑ2, representada en las Figuras 4-5, en un intervalo que corresponde al Sinemuriense superior, cronozonas Obtusum y Oxynotum, y se muestrearon de nuevo algunos niveles 


\section{RODILES E (ER)}
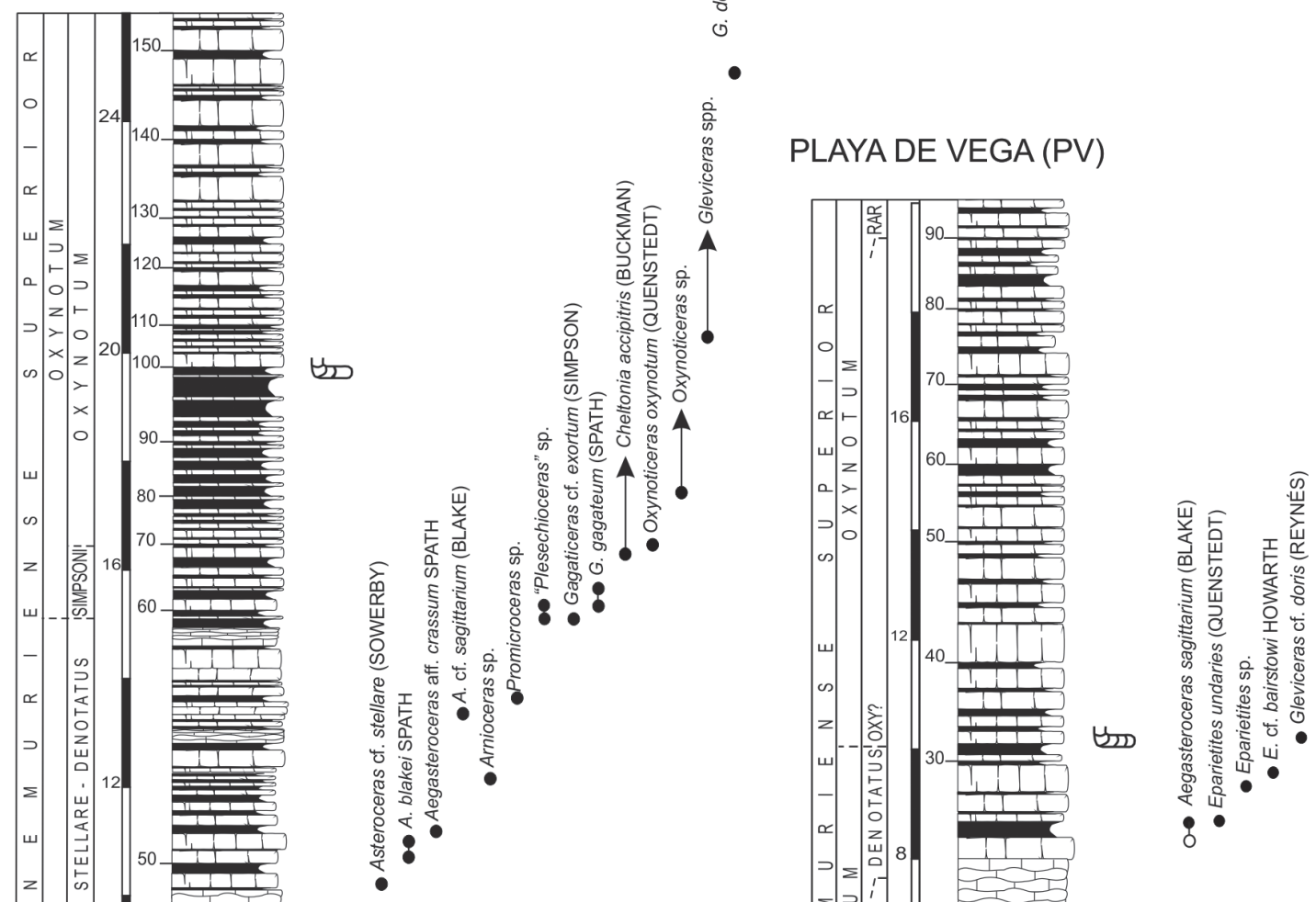

Figura 6. Distribución de los ammonoideos en las secciones de Punta de Rodiles E (A) y de Playa de Vega (B).

de la subcronozona Denotatus en ER, de la subcronozona Obtusum en LLO, de las cronozonas Obtusum y Oxynotum en HU y del tránsito Obtusum-Oxynotum en PV.

Los ammonoideos fueron obtenidos en más de 40 niveles sucesivos de las secciones locales estudiadas (Figs. 4-6) y han permitido inferir la sucesión biocronoestratigráfica que se detalla más adelante en el apartado de cronoestratigrafía.

Por otro lado, para la determinación e interpretación de las secuencias se han tenido en cuenta la ordenación vertical de estructuras sedimentarias inorgánicas (ripples de oleaje, niveles de estratificación cruzada hummocky, laminación paralela, etc), así como de los icnofósiles presentes, la situación de los cuerpos fósiles y la clasificación textural y granulométrica de las calizas y margas. Se han identificado además especialmente las superficies transgresivas de erosión (ravinement) y el mayor o menor grado de irregularidad de las superficies limitantes caliza/marga. 


\section{PALEONTOLOGíA SISTEMÁTICA}

Superfamilia Psilocerataceae Hyatt, 1867

Familia Arietitidae Hyatt, 1875

Subfamilia Arietitinae Hyatt, 1875

Género Arnioceras Hyatt, 1867

Arnioceras spp.

Material. PÑ.120, ER. 55.8, HU.ES1.

Descripción. Se han incluido en este género tres ejemplares mal conservados e incompletos. Uno corresponde a una forma evoluta de unos $4,5 \mathrm{~cm}$ de diámetro, ligeramente deformado, procedente de la sección PÑ, con costillas afiladas, quilla aguda y surcos laterales estrechos y poco profundos. El ejemplar ex situ procedente de la localidad de Huerres es una macroconcha de más de $7 \mathrm{~cm}$ con vueltas internas lisas y las posteriores con costillas rectas, afiladas y cóncavas hacia la cámata de habitación, en número superior a 30 , en la última vuelta visible. Es próximo al figurado por Page (2010; p. 204, Pl. 32, Figs. 9-10) como A. semicostatoides Spath. También, se ha recogido otro ejemplar moderamente evoluto y costillas a lo largo de casi todo el desarrollo ontogénico, que muestra afinidades con los últimos Arnioceras $[A$. aff. arnouldi (Dumortier)].

Distribución estratigráfica. Los especímenes de PÑ y HU proceden de la cronozona Obtusum, subcronozona Obtusum y el de ER a la cronozona Obtusum, parte superior de la subcronozona Stellare, situándose en una posición intermedia entre Asteroceras blakei y Aegasteroceras sagittarium.

Subfamilia Asteroceratinae Spath, 1946

Género Asteroceras Hyatt, 1867

Asteroceras confusum Spath, 1925

(Fig. 8a)

1880-1881 Arietites obtusus (Sowerby); Wright, p. 293 (1881), P1. 21, figs. 3, 4 (1880) (holotipo).

1966 Asteroceras confusum; Guérin-Franiatte, p. 296, Pl. 172.

1974 Asteroceras confusum; Suárez Vega, p. 162, Pl. 2, fig. 1 .

2002 Asteroceras confusum; Howarth, p. 123, Pl. 1, fig. 4; Pl. 2, fig. 1.

2010 Asteroceras confusum; Page, p. 211, Pl. 34, figs. 9-10.
2017 Asteroceras gr. confusum; Dommergues \& Meister, p. 235, fig. 70.

2019 Asteroceras gr. confusum; Meister \& Schlögl, p. 9, figs. 6k, n, 7a, 8a, 9c-f, 11d, e.

Material. PÑ.117s (MUJA.2142, figurado por Suárez Vega, 1974), PÑ.125, LLO.IS1, MUJA.5026, HU.IS2.

Descripción. El espécimen PÑ.117s (Fig. 8a) corresponde a una concha casi completa de $22 \mathrm{~cm}$ de diámetro que conserva alrededor de $2 / 3$ de la cámara de habitación, ligeramente comprimida y ombligo del $42 \%$ en relación con el diámetro máximo. La costulación es relativamente gruesa, recta con una suave inflexión en la región ventrolateral y región ventral con quilla y dos surcos bien diferenciados que se suavizan ligeramente en la última vuelta. El resto de ejemplares atribuidos a esta especie son fragmentos correspondientes a vueltas internas en los que se observan costillas algo más finas, más apretadas y con los elementos de la región ventral menos marcados.

Posición estratigráfica. Cronozona Obtusum, parte inferior de la subcronozona Obtusum.

Asteroceras aff. confusum Spath, 1925

(Fig. 7b)

1974 Asteroceras gr. obtusum? (Sow.); Suárez Vega, p. 41.

?1993 Asteroceras aff. confusum; Dommergues, Pl. 2, fig. 3.

1993 Asteroceras aff. confusum; Meister \& Böhm, Pl. 4, figs. 7, 9, 11.

1997a Asteroceras aff. confusum; Corna et al., Pl. 4, fig. 3.

2019 Asteroceras aff. confusum; Meister \& Schlögl, p. 9 , figs. $10 \mathrm{e}-\mathrm{g}$.

Material. MUJA.3443, PÑ.IS1, PÑ.IS2, HU.IS3, HU. IS4, HU.IS5.

Descripción. Ejemplares de talla grande próximos a A. confusum que pueden alcanzar los $46 \mathrm{~cm}$ de diámetro, pero con región ventral y flancos abombados, costillas más numerosas y ombligo más pequeño $(37 \%)$ que en la especie nominal.

Posición estratigráfica. Cronozona Obtusum, parte basal de la subcronozona Obtusum.

Asteroceras obtusum (Sowerby, 1817)

(Fig. 8b) 

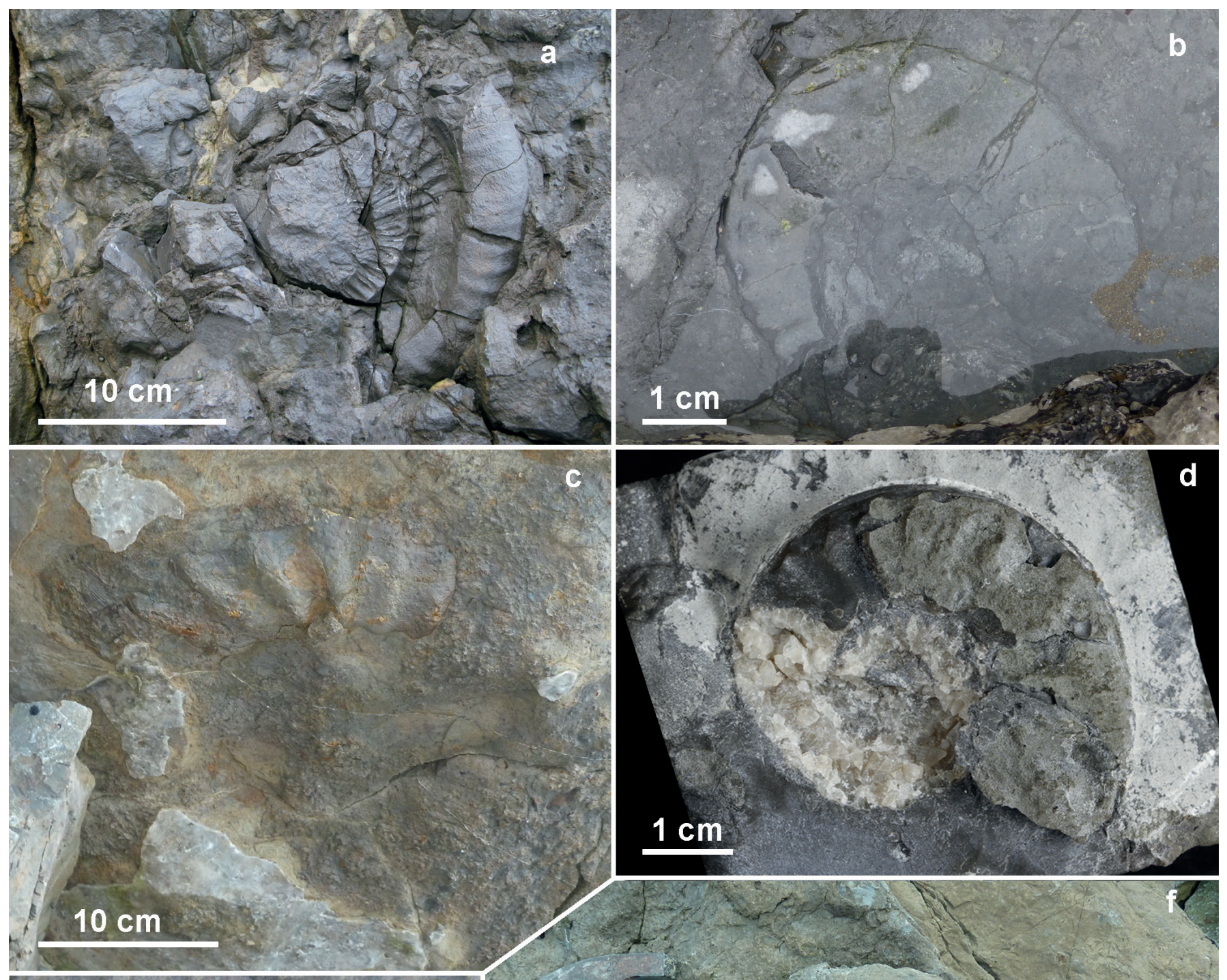

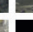
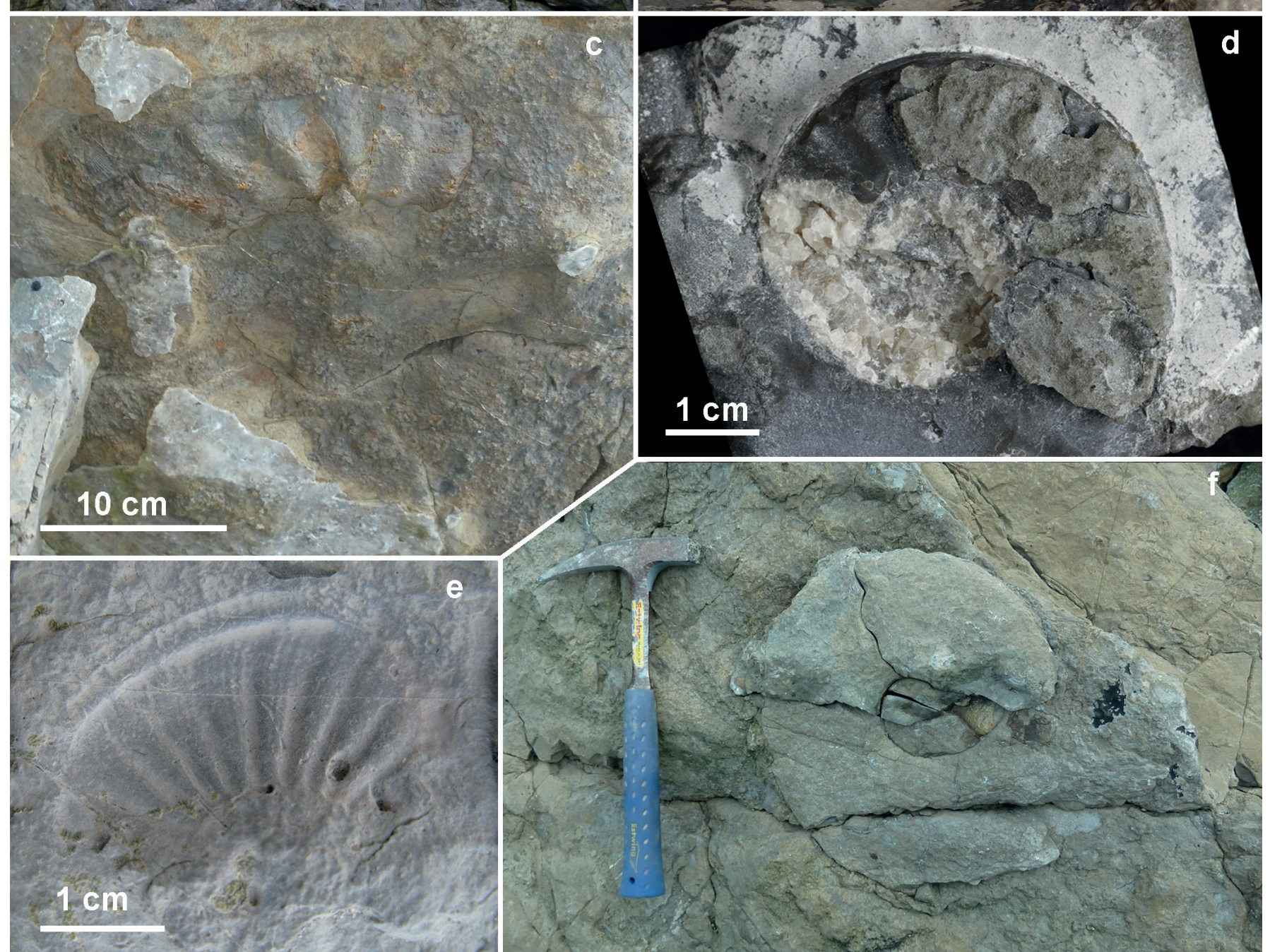

Figura 7. Ejemplares reconocidos en campo. a) Epophioceras aff. longicella, subcronozona Obtusum, La Llastra O, LLO.IS2. b) Asteroceras aff. confusum, subcronozona Obtusum, Peñarrubia, PÑ.IS1. c) Aegasteroceras aff. crassum, subcronozona Stellare, E Rodiles, ER.53. d) Eparietites undaries, subcronozona Denotatus, Huerres, MUJA.3849. e) Eparietites impendens, subcronozona Denotatus, Huerres, HU.IS6. f) Paroxynoticeras salisburgense, subcronozona Oxynotum, Huerres, HU.IS8. 
1817 Ammonites obtusus Sowerby, p. 151, P1. 167.

1966 Asteroceras obtusum; Guérin-Franiatte, p. 294, P1. 170 (lectotipo).

2010 Asteroceras obtusum; Page, p. 211, Pl. 34, figs. $3-4$.

Material. PÑ.142, PÑ.146i (cf), MUJA.5027.

Descripción. Ejemplares de pequeño tamaño con costillas fuertes y muy proyectadas hacia adelante en la región ventrolateral, ombligo aproximado de un 45\% y región ventral con quilla y surcos bien marcados.

Posición estratigráfica. Cronozona Obtusum, parte superior de la subcronozona Obtusum-parte inferior basal de la subcronozona Stellare.

\section{Asteroceras cf. margaritoides Spath, 1925}

(Fig. 8c)

cf..2010 Asteroceras margaritoides; Page, p. 212, P1. 34, figs. 5-8.

Material. PÑ.146s (2 ejemplares), PÑ.190 (MUJA.2038).

Descripción. Asteroceras de talla relativamente pequeña, más involutos que las especies precedentes, con flancos aplanados que pasan a ser algo más convexos con el crecimiento. Costillas ligeramente proversas y región ventral con quilla y surcos marcados en las vueltas internas que se suavizan levemente en la cámara de habitación. El ejemplar PÑ.190 (MUJA.2038), muestra un notable parecido con algunas especies de Caenisites, como $C$. turneri, de la que se diferencia por tener un ombligo más pequeño y unas costillas menos numerosas. Uno de los ejemplares procedentes de PÑ. 146s corresponde a las vueltas internas de un individuo que tiene el ombligo algo más amplio que el de los otros especímenes de $A$. margaritoides pero menos que el de A. obtusum.

Posición estratigráfica. Cronozona Obtusum, parte inferior de la subcronozona Stellare.

Asteroceras stellare (Sowerby, 1815)

(Figs. 8d-e)

1815 Ammonites stellaris Sowerby, p. 211, P1. 93.

1880-1881 Arietites stellaris; Wright, p. 22, figs. 3-5 (1880) (lectotipo); p. 295 (1881).

1882 Aegoceras sagittarium; Wright, p. 355, P1. 52, figs. 1-3.
1961 Asteroceras stellare; Dean et al., Pl. 67, fig. 2. 1966 Asteroceras stellare; Guérin-Franiatte, Pls. 153 (holotipo), 154, 155.

1993 Asteroceras stellare; Dommergues, Pl. 1, fig. 8. 1997b Asteroceras stellare; Corna et al., P1. 10, fig. 3. 2010 Asteroceras stellare; Page, P1. 34, figs. 1, 2.

2017 Asteroceras gr. stellare; Dommergues \& Meister, p. 238 , fig. 74 .

2019 Asteroceras stellare; Meister \& Schlögl, p. 17, figs. 5c-e, 6e-h, 11f, g, 12a, d, 13, 14a, b, 15a-g, 16ad, $18 \mathrm{c}, \mathrm{d}$.

Material. PÑ.204 (MUJA.3465, molde de escayola obtenido directamente en el campo, Col. Suárez Vega,), ER.48 (estudiado por García-Martínez, 2001), MUJA.5028, MUJA.5029.

Descripción. El espécimen PÑ.204 (Fig. 8d) corresponde a un individuo de Asteroceras de talla grande, involuto, flancos suavemente convergentes y con una altura grande en la última vuelta y costillas rectas ligeramente proversas desde la mitad de los flancos. Para esta talla, los surcos de la región ventral están poco marcados y se convierten en suaves áreas planas. Es uno de los Asteroceras más involutos de todos los que se han identificado en Asturias. El espécimen MUJA.5028 (Fig. $8 \mathrm{e}$ ) es próximo a $A$. margaritoides y las vueltas internas muestran la región ventral parecida a la de $C$. turneri.

Posición estratigráfica. Cronozona Obtusum, subcronozona Stellare.

\section{Asteroceras blakei Spath, 1925}

(Figs. 8f-h)

1925 Asteroceras blakei Spath, p. 264, fig. 5 (holotipo). 1966 Asteroceras blakei; Guérin-Franiatte, Pl. 179, 180. 1993 Aegasteroceras blakei; Dommergues, Pl. 1, fig. 10; Pl. 2, fig. 3.

1997a Aegasteroceras blakei; Corna et al., p. 110, P1. 4, fig, 5 .

2002 Asteroceras blakei; Howarth, p. 124, P1. 2, Fig. 2. 2016 Asteroceras blakei; Edmunds et al., p. 152, figs. 4d-k, 5a-e.

Material. PÑ.206, PÑ.210 (MUJA.3466), ER.50, ER.52. 


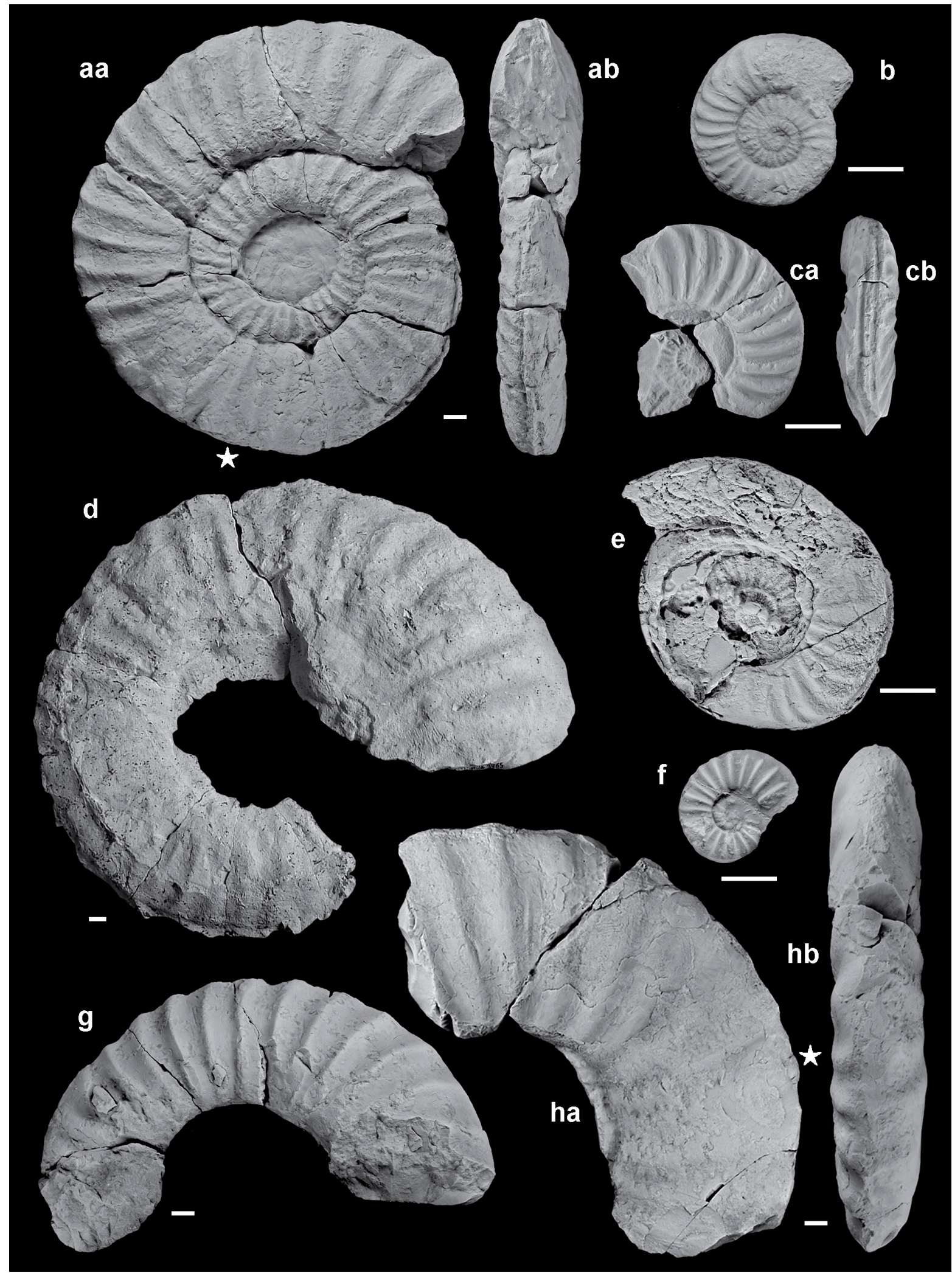

Figura 8. a) Asteroceras confusum (refiguración del ejemplar de Suárez Vega, 1974, P1. 2, Fig. 1), Subcronozona Obtusum, Peñarrubia, PÑ.117s (MUJA.2142). b) Asteroceras obtusum, Subcronozona Obtusum, Villar, MUJA.5027. c) Asteroceras cf. margaritoides, Subcronozona Stellare, Peñarrubia, PÑ.190 (MUJA.2038). d, e) Asteroceras stellare; d) molde en escayola, Peñarrubia, (MUJA.3465), Subcronozona Stellare, Peñarrubia, PÑ.204; e) Subcronozona Stellare, La Llastra O, MUJA.5028. f-h) Asteroceras blakei; f) vaciado en látex, Subcronozona Stellare, Peñarrubia, PÑ.206; g) Subcronozona Stellare, Peñarrubia, PÑ.210 (MUJA.3466); h) Subcronozona Stellare, E Rodiles, ER.50. La estrella señala el comienzo de la cámara de habitación. Escala gráfica $=1 \mathrm{~cm}$. 
Descripción. Asteroceras moderadamente involuto, con costillas que se curvan suavemente hacia delante en el margen ventrolateral y, en las vueltas internas (Fig. 8f), con quilla ventral rodeada por áreas planas donde las costillas se inflexionan dándole una apariencia tricarenada. La sección de la vuelta cambia con el crecimiento de modo que los flancos se estrechan, la sección adquiere un aspecto ovalado y la quilla se suaviza y casi desaparece en la parte más externa, de forma que las costillas dan la sensación de cruzar la región ventral. Este carácter es el que ha llevado a algunos autores a incluirlo en el género Aegasteroceras.

Posición estratigráfica. Cronozona Obtusum, parte superior de la subcronozona Stellare.

Asteroceras cf. suevicum (Quenstedt, 1884)

(Fig. 9a)

cf. 1884 Ammonites obtusus suevicus Quenstedt, p. 146, Pl. 20, fig. 1.

cf. 1966 Asteroceras suevicum; Guérin-Franiatte, p. 289, Pl. 163 (refiguración del holotipo), 166.

1974 Asteroceras suevicum?; Suárez Vega, p. 40.

1985 Asteroceras cf. suevicum; Braga et al., p. 97, $\mathrm{Pl}$. 1, fig. 5 .

1998 Asteroceras cf. suevicum; Blau, p. 203, Pl. 2, figs. 13-16; Pl. 14, fig. 6.

2019 Asteroceras cf. suevicum; Meister \& Schlögl, p. 23, figs. $6 \mathrm{j}, \mathrm{o}, 17 \mathrm{a}, \mathrm{b}, 18 \mathrm{a}, \mathrm{b}$.

Material. PÑ.210 (MUJA.3467, molde en escayola).

Descripción. Corresponde a las vueltas internas de un ejemplar próximo a esta especie por el crecimiento relativamente lento, surcos ventrales poco profundos y ornamentación de costillas fuertes y rectas que se inflexionan hacia delante en la región ventral.

Posición estratigráfica. Cronozona Obtusum, subcronozona Stellare.

Género Aegasteroceras Spath, 1925

Aegasteroceras aff. crassum Spath, 1925

(Fig. 7c)

1882 Aegasteroceras sagittarium Blake; Wright, p. 355, Pl. 52A, figs. 1, 2 (holotipo de Aegasteroceras crassum Spath, 1925).

1925 Aegasteroceras crassum Spath, p. 266.

\section{Material. ER.53.}

Descripción. Ejemplar de talla grande de más de $30 \mathrm{~cm}$ de diámetro, mal conservado, que no ha podido ser asimilado a ninguna especie conocida del género Aegasteroceras y con costillas fuertes y espaciadas como las de $A$. crassum, aunque de talla es mucho mayor que la del espécimen figurado por Howarth (2002; Pl. 2, fig. 4).

Posición estratigráfica. Cronozona Obtusum, parte superior de la subcronozona Stellare.

Aegasteroceras sagittarium (Blake, 1876)

(Fig. 9b)

1876 Aegoceras sagittarium Blake, p. 276, Pl. 7, fig. 2A (lectotipo), 2B paralectotipo).

1880/82 Aegoceras acuticostatum; Wright, p. 371 (1882), PI. 35, figs. 1-3 (1880).

1925 Aegasteroceras simile; Spath, p. 265, fig. 6a.

1966 Aegasteroceras sagittarium; Guérin-Franiatte, p. 312, Pl. 191, fig. 1.

2002 Aegasteroceras sagittarium; Howarth, p. 124, Pl. 1, fig. 7.

2016 Asteroceras sagittarium; Edmunds et al., p. 154, figs. 8a-1, 9e-g.

Material. ER.55.14, PV.21t (cf.) (MUJA.4703), PV.22 (MUJA.4705).

Descripción. En las vueltas internas, la sección es alta, comprimida y con flancos paralelos, quilla ventral bien definida limitada por dos áresa ventrales planas y lisas para un, diámetro de alrededor del 38\% y entre 13-14 costillas en media vuelta (para un tamaño de unos $5 \mathrm{~cm}$ de diámetro). Después, los flancos comienzan a abombarse, la quilla se hace progresivamente más suave, las áreas planas ventrales se inclinan y se suavizan lo que hace que la sección de la vuelta se haga elipsoidal, la región ventral se arquea y las costillas atraviesan la región ventral con muy poco relieve.

Posición estratigráfica. Cronozona Obtusum, parte superior de la subcronozona Stellare.

Género Eparietites Spath, 1924

Eparietites undaries (Quenstedt, 1884)

(Fig. 7d) 


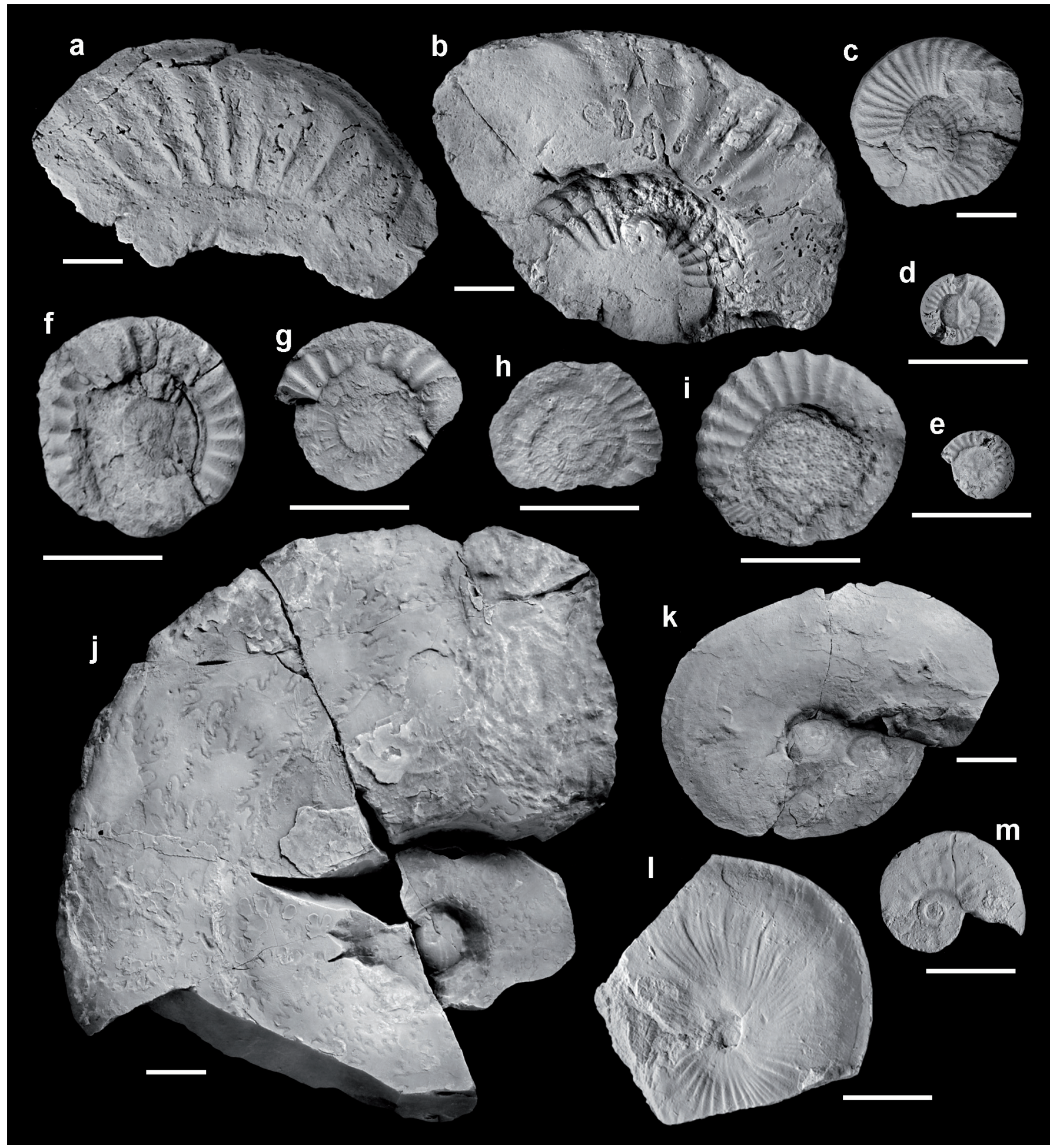

Figura 9. a) Asteroceras cf. suevicum, molde en escayola, Subcronozona Stellare, Peñarrubia, PÑ.210 (MUJA.3467). b) Aegasteroceras sagittarium, Subcronozona Denotatus, Playa de Vega, PV.22 (MUJA.4705). c) Eparietites impendens, Subcronozona Denotatus, Peñarrubia, PÑ.260s. d, e) Palaeoechioceras sp.; Subcronozona Simpson, La Llastra O; d) MUJA.4709; e) MUJA.4710. f, g) Gagaticeras cf. exortum, Subcronozona Simpsoni, E Rodiles; f) ER.58.1; g) ER.58.2, vaciado en látex. h, i) Gagaticeras gagateum, Subcronozona Simpsoni, E Rodiles; h) ER.60.1 vaciado en látex; i) ER.60.2. j) Paroxynoticeras salisburgense, Subcronozona Oxynotum, Peñarrubia, PÑ.300. k, l) Oxynoticeras oxynotum; k) Subcronozona Oxynotum, Peñarrubia, PÑ.280; l) Subcronozona Oxynotum, E Rodiles, ER.69. m) Cheltonia accipitris, Subcronozona Simpsoni, E Rodiles, ER.68. Escala gráfica $=1 \mathrm{~cm}$. 
1884 Ammonites undaries Quenstedt, Pl. 20, figs. 2-3 (lectotipo), 4-6.

1966 Eparietites undaries; Guérin-Franiatte, p. 319, Pls. 200-203.

1976 Asteroceras (Eparietites) undaries; Schlegelmilch, Pl. 19, fig. 3.

Material. PV.22+0,07 (MUJA.4706), MUJA.3849.

Descripción. Ejemplares incompletos con sección de la vuelta ligeramente triangular, un poco más alta que ancha con los flancos planos, margen ventral bastante amplio, tricarenado y bisurcado y quilla media bastante alta; pared umbilical vertical, ombligo relativamente abierto que representa un $33 \%$ del diámetro y que disminuye ligeramente durante el desarrollo ontogénico y costulación menos fuerte y apretada que en E. impendens y que se va suavizando con el crecimiento.

Posición estratigráfica. Cronozona Obtusum, parte inferior de la subcronozona Denotatus.

Eparietites cf. bairstowi Howarth, 2002

2002 Eparietites bairstowi sp. nov., Howarth, p. 124, Pl. 2, fig. 8; Pl. 3 (holotipo).

Material. PV.27s Se trata de un ejemplar situado en un lugar poco accesible de la sección (Comas-Rengifo \& Goy, 2010) que fue destruido durante una tormenta, pero se conserva una foto anterior y un fragmento del ejemplar, MUJA.4707.

Descripción. Corresponde a un ejemplar de unos 45 $\mathrm{cm}$ de diámetro. Es posiblemente la especie de Eparietites más antigua junto con E. undaries que tiene un desarrollo ontogénico similar y que podría corresponder a su microconcha. También es más evoluta que las especies siguientes con un diámero entre el 39 y el $37 \%$, frente a un $33-29 \%$ de E. undaries y menos del $29 \%$ de E. impendens. El holotipo de Howarth (2002) tiene vueltas masivas, con una sección de subrectángular a subcuadrada en la que los flancos convergen ligeramente hacia la región ventral, que es tricarenada-bisurcada con surcos suaves que bordean la quilla ventral y desaparecen progresivamente en los tamaños más grandes.

Posición estratigráfica. Cronozona Obtusum, subcronozona Denotatus.

Eparietites impendens (Young \& Bird, 1828)

(Figs. 7e, 9c)
1828 Ammonites impendens Young \& Bird, p. 266.

1844 Ammonites fowleri; J. Buckman, Pl. 12, fig. 7.

1855 Ammonites denotatus; Simpson, p. 76.

1881 Arietites collenoti (d'Orbigny); Wright, p. 304, Pl. 6, fig. 1; Pl. 22b, figs. 1-3.

1912 Arietites denotatus; Buckman, Pls. 67A, B.

1919 Arietites impendens; Buckman, Pl. 120 (holotipo).

1961 Eparietites impendens; Dean et al., Pl. 66, fig. 4.

1966 Ammonites fowleri; Guérin-Franiatte, p. 315, Pl. 197, figs. 1-2, fig.text. 170.

2002 Eparietites impendens; Howarth, p. 124, Pl. 1, fig. 6; Pl. 4, fig. 1.

2003 Eparietites fowleri; Meister \& Friebe, p. 33, Pl. 9, fig.1.

2005 Eparietites impendens; Dommergues et al., p. 680, Pl. 1, figs. 10-13; Pl. 2, figs. 1-2.

Material. PÑ.230 (cf.), PÑ.242, PÑ.248s, PÑ.260s, HU.IS6.

Descripción. Conchas de tamaño relativamente pequeño, vueltas menos anchas en el borde umbilical suave y redondeado, quilla ventral diferenciada, flanqueada por dos áreas estrechas planas y después márgenes ventrolaterales angulosos, ombligo muy variable que representa entre un 29 y un $22 \%$ del díametro en los diferentes morfotipos (24-22\% en el holotipo de la especie) y costillas apretadas y ligeramente flexionadas hacia delante en su extremo distal. En el ejemplar de la Figura 7 e se observan finas costillas.

Posición estratigráfica. Cronozona Obtusum, subcronozona Denotatus y cronozona Oxynotum, subcronozona Simpsoni.

Eparietites glaber Guérin-Franiatte, 1966

(Fig. 10a)

1966 Eparietites glaber Guérin-Franiatte, p. 316, Pl. 198, figs. 1 (holotipo), 2; fig.-text 171.

1993 Eparietites glaber; Dommergues, Pl. 3, figs. 2, 3.

1995 Eparietites glaber; Dommergues et al., p. 174, Pl. 7, fig. 1.

1998 Eparietites glaber; Blau, Pl. 2, figs. 9-11.

2003 Eparietites glaber; Meister \& Friebe, p. 34, Pl. 6, fig. 3; Pl. 9, fig. 3.

2005 Eparietites gr. glaber; Dommergues et al., p. 681, Pl. II, figs. 3-7. 


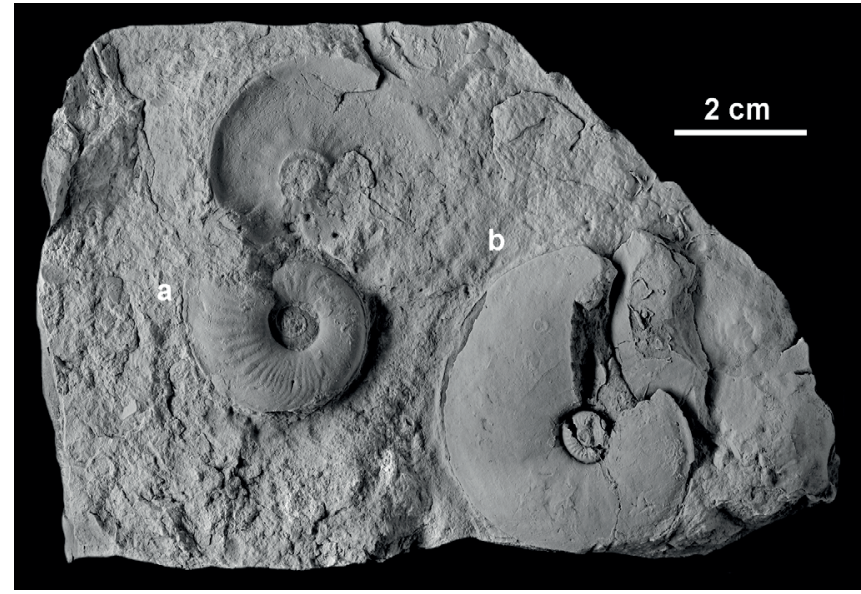

Figura 10. a) Eparietites glaber, subcronozona Simpsoni, Peñarrubia. b) Oxynoticeras simpsoni, PÑ.270 (MUJA.4721).

Material. PÑ.248i (cf.), PÑ.270 (MUJA.4721.1, MUJA.4721.2).

Descripción. Conchas de pequeño tamaño, involutas, comprimidas, que miden por lo general entre 7 y $8 \mathrm{~cm}$, con omligo que representa un $22-20 \%$ del diámetro total, costillas muy finas, ligeramente proversas, irregulares, apretadas en las primeras vueltas y que se atenuan con el crecimiento y casi se convierten en ondulaciones. La región ventral es estrecha, afilada, con quilla aguda bordeada de dos estrechas áreas planas.

Posición estratigráfica. Cronozona Obtusum, parte superior de la subcronozona Denotatus y cronozona Oxynotum, subcronozona Simpsoni.

Género Epophioceras Spath, 1924

\section{Epophioceras aff. longicella (Quenstedt, 1883)}

(Fig. 7a)

aff. 1883 Ammonites latisulcatus longicella Quenstedt, p. 89 , PI. 12, fig. 5 (holotipo).

1924 Epophioceras latisulcatus longicella; Spath, p. 204.

1985 Epophioceras longicella; Corna, Pl. 9, figs. 1-2.

?2002 Epophioceras $\mathrm{cf}$. longicella; Hillebrandt, Pl. 7, fig. 1 (=E. cf. cognitum Guérin-Franiatte; Hillebrandt, 1981, Pl. 3, fig. 2).

2002 Epophioceras longicella; Rakús \& Guex, Pl. 13, figs. 1-4, 7.

2010 Epophioceras longicella, Page, p. 215, Pl. 35, fig. 6 .
2017 Epophioceras aff. longicella; Dommergues \& Meister, p. 243, fig. 83.

2019 Epophioceras $\mathrm{cf}$. longicella; Meister \& Schlögl, p. 27, figs. 20c, e, 22e, f.

\section{Material. LLO.IS2.}

Descripción. Ejemplar incompleto de unos $19 \mathrm{~cm}$, forma muy evoluta, vueltas casi tan anchas como altas con una sección subcircular, región ventral con quilla baja bien marcada que está limitada por áreas planas, con un ombligo de alrededor del $67 \%$, gran densidad de la costulación que crece regularmente e intensidad a lo largo del desarrollo ontogénico, con costillas que tienen una fuerte inflexión hacia delante y que se atenúan en la última vuelta. El ejemplar figurado es más involuto que el holotipo de E. longicella. También es notablemente más involuto que el ejemplar figurado por Meister \& Schlögl (2019). Muestra algunas similitudes con E. cf. longicella de Hillebrandt (2002), en la talla y el tamaño del ombligo, pero no en la costulación que es más densa y proversa en el espécimen asturiano.

Posición estratigráfica. Cronozona Obtusum, parte inferior basal de la subcronozona Obtusum.

\section{Epophioceras cf. landrioti (d'Orbigny, 1849)}

1849 Ammonites landrioti d'Orbigny, p. 213.

1907 Ammonites landrioti; Thèvenin, p. 94, Pl. 4, figs. 4-5.

1966 Epophioceras landrioti; Guérin-Franiatte, p. 329, P1. 217 (holotipo).

1985 Epophioceras landrioti; Braga et al., Pl. 1, fig. 1.

1998 Epophioceras landrioti; Blau, p. 205, Pl. II, fig. 12.

2003 Epophioceras gr. landrioti; Meister \& Friebe, p. 33, Pl. 9, fig. 4.

\section{Material. MUJA.2044.}

Descripción. Ejemplar mal conservado de unos $12 \mathrm{~cm}$ de diámetro, evoluto, en el que el ombligo representa más del $70 \%$, sección de la vuelta subcuadrada, casi tan ancha como alta y con los flancos redondeados, región ventral con una quilla fuerte, que persiste hasta la última vuelta, costillas inflexionadas hacia adelante, medianamente apretadas que se atenúan con el crecimiento y que a veces pueden estar ligeramente agrupadas o engrosadas. 
Posición estratigráfica. Cronozona Obtusum, subcronozona Stellare.

\section{Epophioceras sp.}

\section{Material. HU.IS7.}

Descripción. Ejemplar muy evoluto de unos $20 \mathrm{~cm}$ de diámetro que no se puede determinar a nivel específico porque presenta un fuerte desgaste debido a la abrasión del mar.

Posición estratigráfica. Cronozona Obtusum, parte inferior basal de la subcronozona Obtusum. Se sitúa ligeramente por debajo de los primeros especímenes de $A$. aff. obtusum.

Familia Echioceratidae Buckman, 1913

Género Palaeoechioceras Spath, 1929

Palaeoechioceras sp.

(Figs. 9d-e)

Material. PÑ.270 (MUJA.4722), MUJA.4709, MUJA.4710.

Descripción. Fragmoconos incompletos, globosos, lisos y con la sección deprimida que posteriormente se hace mas circular o ligeramente comprimida con costillas romas, proversas y espaciadas, que pasan a ser más rectas y agudas a medida que los especímenes crecen y son más evolutos y se proyectan en la región ventral aplanada, sin quilla, pero luego se suavizan. Se trata de formas próximas a las figuradas por Getty (1973; Pl. 1, figs. 1-2).

Posición estratigráfica. Cronozona Oxynotum, parte inferior de la subcronozona Simpsoni.

Género Gagaticeras Buckman, 1913

Gagaticeras cf. exortum (Simpson, 1855)

(Figs. 9f-g)

1855 Ammonites exortus Simpson, p. 44.

1910 Echioceras exortum; Buckman, Pl. 10, figs. 2-3 (neotipo designado por Howarth, 1962, p. 106).

2002 Gagaticeras exortum; Howarth, p. 125, Pl. 2, fig. 7.

Material. PÑ.248i, PÑ.248s, ER.58.1-4, MUJA.4711.

Descripción. Ejemplares de pequeña talla, evolutos, con ombligo relativamente amplio que no sobrepasa el
$50 \%$ del diámetro, sección de las vueltas por lo general algo más anchas que altas, redondeadas en las vueltas internas y luego deprimidas. Las costillas son retroversas y densas en las vueltas internas, aunque en el ejemplar de la Figura $9 f$ son difíciles de observar porque está ligeramente deformado.

Posición estratigráfica. Cronozona Oxynotum, parte inferior de la subcronozona Simpsoni.

Gagaticeras gagateum (Young \& Bird, 1828)

(Figs. 9h-i)

1828 Ammonites gagateus Young \& Bird, p. 255, Pl. 12, fig. 7 .

1913 Gagaticeras gagateum; Buckman, P1. 78 (holotipo).

1962 Gagaticeras gagateum; Howarth, p. 102, Pl. 14, fig. 6 .

1993 Gagaticeras gagateum; Dommergues, p. 131, Pl. 6 , figs. $2,3$.

?1996 Gagaticeras gagateum; Bernad \& Martínez, p. 4, P1. 1, fig. 5.

1997a Gagaticeras gagateum; Corna et al., p. 110. Pl. 4, fig. 7.

?2005 Gagaticeras gr. gagateum; Dommergues et al., p. 684 , Pl. 4, figs. 6-12.

Material. PÑ.248s, PÑ.248t, PÑ.249, PÑ.250.1-3 (MUJA.4723, MUJA.4724, MUJA.4725), PÑ.250s.1-3, ER.60.1-6, ER.62, MUJA.4714.

Descripción. Núcleo de sección deprimida, evoluto con las vueltas externas y medias circulares o ligeramente comprimidas, ombligo sobre el $50-58 \%$ del diámetro y quilla baja que puede estar presente en las vueltas externas. Costillas robustas, romas y muy separadas en las vueltas internas que pasan a costillas fuertes, por lo general rectas y retroversas en las vueltas medias y externas. Estas costillas atraviesan la región ventral sin debilitarse, excepto algunas veces en el núcleo, y pueden proyectarse ligeramente hacia adelante.

Posición estratigráfica. Cronozona Obtusum, subcronozona Simpsoni.

Género Plesechioceras Trueman \& Williams, 1925

$$
\text { «Plesechioceras»sp. }
$$

Material. ER.58, ER.60. 
Descripción. Dos especímenes, mal conservados, que se han recogido asociados a $G$. gagateum. Presentan una morfología parecida a Plesechioceras aff. platypleura (Dommergues, 1993) que procede de la Zona Oxynotum de Borgoña, especie a la que fueron atribuidos por Comas-Rengifo et al. (2010). Sin embargo, las diferencias notables que muestran con la especie tipo del género Plesechioceras no permiten descartar que nuestros ejemplares pudieran corresponder a alguna especie de Palaeoechioceras ya que, en la misma posición, en la sección de LLO, se han encontrado representantes de este género (Figs. 9d-e).

Posición estratigráfica. Cronozona Oxynotum, subcronozona Simpsoni.

Familia Oxynoticeratidae Hyatt, 1867

Género Oxynoticeras Hyatt, 1867

Oxynoticeras simpsoni (Simpson, 1843)

(Fig. 10b)

1843 Ammonites simpsoni Simpson, p. 37.

1912 Aetonoceras simpsoni; Buckman, Pl. 66A, B (holotipo).

1925 Oxynoticeras simpsoni; Spath, p. 110, fig. g.

1961 Oxynoticeras simpsoni; Dean et al., Pl. 67, fig. 4.

1997a Oxynoticeras simpsoni; Corna et al., p. 110, Pl. 4, fig. 12.

2002 Oxynoticeras simpsoni; Howarth, p. 129, Pl. 4, figs. 5,8 .

Material. PÑ.270t, MUJA.4721.3, MUJA.4721.4, PÑ.276.

Description. Oxiconos de omligo pequeño (19\% del diámetro), región ventral lanceolada, sin quilla y borde umbilical no diferenciado, ya que los flancos llegan con una pendiente suave hasta la pared umblical muy poco marcada y que parece fusionarse con los flancos suavemente convexos. Conchas casi lisas o con suaves ondulaciones, pero en el ejemplar figurado se observan costillas bien marcadas en las vueltas internas, al menos hasta los $9 \mathrm{~mm}$ de diámetro. Según Howarth (2002), $O$. simpsoni es una especie distintiva que tiene un ombligo más grande y vueltas más gruesas que $O$. oxynotum. En Asturias, como en la sección de Robin Hood's Bay, el rango estratigráfico de $O$. simpsoni se superpone en parte con el de Eparietites, de los que difiere principalmente por su ombligo menor y por la sección de la vuelta.
Posición estratigráfica. Cronozona Obtusum, subcronozona Simpsoni.

Oxynoticeras oxynotum (Quenstedt, 1843)

(Figs. 9k-1)

1843 Ammonites oxynotus Quenstedt, p. 161.

1845 Ammonites oxynotus; Quenstedt, p. 98, Pl. 5, fig. 11 (holotipo).

1961 Oxynoticeras oxynotum; Dean et al., Pl. 66, fig. 5.

1974 Oxynoticeras gr. oxynotum; Suárez Vega, p. 130, Pls. 3, 4.

1982 Oxynoticeras gr. oxynotum?; Comas-Rengifo, $\mathrm{p}$. 266, P1. 22, fig. 6.

1990 Oxynoticeras simpsoni; Hollingworth et al., P1. 1, figs. 7-9.

1995 Oxynoticeras gr. oxynotum; Dommergues et al., p. 175 , Pl. 9, fig. 2.

2002 Oxynoticeras oxynotum; Howarth, p. 129, Pl. 4, fig. 4.

2003 Oxynoticeras oxynotum; Meister \& Friebe, p. 34, P1. 9, figs. 5, 7.

Material. PÑ.280, ER.69, MUJA.2046 (figurado por Suárez Vega).

Descripción. Moldes internos de conchas de talla mediana (menos de $17 \mathrm{~cm}$ ), involutas, ombligo pequeño y relativamente profundo entre el 13 y el $17 \%$ de diámetro $(13,5 \%$ para el ejemplar de la Figura 81$)$ y sección de la vuelta ojival, muy estrecha (menos del $8 \%$ del diámetro para el ejemplar de Pozo de los Lobos, MUJA.2046) con la máxima anchura situada en el tercio interno y el borde umbilical suavemente diferenciado. Flancos ligeramente convexos y casi paralelos desde el ombligo hasta el tercio externo donde se marca un cambio de pendiente, haciéndose convergentes. Región ventral, estrecha y afilada con quilla poco elevada, pero bien diferenciada, que pasa insensiblemente a los flancos. Costillas radiales, proversas y bien dibujadas hasta algo más de la mitad de la altura de la vuelta, que después se difuminan y, casi a partir de la ruptura de pendiente del flanco, vuelven a aparecer dirigidas hacia delante, en número bastante mayor y unas más afiladas que otras, dando a la región ventral un aspecto ondulado.

Posición estratigráfica. Cronozona Obtusum, parte inferior de la subcronozona Oxynotum.

Género Cheltonia Buckman, 1904 
Cheltonia accipitris (J. Buckman, 1844)

(Fig. 9m)

1844 Ammonites accipitris J. Buckman, p. 102 (holotipo).

1990 Cheltonia accipitris; Hollingworth et al., p. 167, Pl. 1, figs. 1, 2.

1997a Cheltonia accipitris; Corna et al., p. 110, Pl. 4, figs. 10, 11.

1976 Cheltonia accipitris; Schlegelmilch, p. 59, Pl. 22, fig. 13.

1982 Cheltonia accipitris; Comas-Rengifo, p. 271, Pl. 2, fig.7.

1990 Cheltonia accipitris; Hollingworth et al., Pl.1, figs. 10, 11.

\section{Material. ER.68.3.}

Descripción. Sección de la vuelta subrectangular, comprimida, más alta que ancha, con borde umbilical mal definido y redondeado, pared umbilical convexa y poco inclinada, flancos casi planos y región ventral, aplanada con una quilla poco elevada con crenulaciones fuertes y espaciadas, dirigidas hacia delante. Ornamentación irregular, poco desarrollada, formada por costillas gruesas, bien marcadas en la parte interna del flanco, que luego se suavizan, para volver a pronunciarse en el borde externo y cruzar la región ventral, dando lugar a crenulaciones. Peristoma liso e inclinado hacia delante.

Posición estratigráfica. Cronozona Oxynotum, parte inferior de la subcronozona Oxynotum.

Género Gleviceras Buckman, 1918

Gleviceras cf. doris (Reynès, 1879)

cf. 1879 Ammonites doris Reynès, Pl. 41, figs. 13-15.

1914 Oxynoticeras doris; Pia, p. 7, Pl. 1, fig.1; Pl. 8, fig. 1.

2002 Oxynoticeras doris; Howarth, p. 130, P1. 4, fig. 7.

Material. ER.106; ER.150; PV.32 (MUJA.4704).

Descripción. Fragmoconos incompletos de conchas de tipo oxicono con talla grande, ombligo pequeño (entre el 25-15\%), sección de la vuelta ovalada, flancos redondeados, región ventral relativamente ancha, quilla afilada pero suave y costillas falciformes débiles.
Posición estratigráfica. Cronozona Oxynotum, parte superior de la subcronozona Oxynotum.

Género Paroxynoticeras Pia, 1914

Paroxynoticeras salisburgense (Hauer, 1856)

(Figs. 7f, 9j)

1856 Ammonites salisburgensis Hauer, p. 47, Pl. 13, figs. 1-3 (lectotipo, designado por Donovan \& Forsey, 1973, p. 9).

1914 Paroxynoticeras salisburgense; Pia, p. 18, 73, Pl.1, fig. 2; Pl. 7, fig. 22; Pl. 13, fig. 12.

1998 Paroxynoticeras salisburgense; Blau, p. 221, Pl. 2, figs. 1-4, 6, 9, 16.

1999 Paroxynoticeras salisburgense; Rakús, p. 326, Pl. 1, fig. 3, text-fig. 10.

2005 Paroxynoticeras cf. salisburgense; Dommergues et al., p. 683, Pl. 3, figs. 2, 3.

Material. PÑ. 291, PÑ.296, PÑ.300, PÑ.306, HU.IS8, HU.IS9.

Descripción. Platiconos a oxiconos con vueltas comprimidas que alcanzan tamaños grandes hasta más de $30 \mathrm{~cm}$ de diámetro cuando conservan la cámara de habitación, ombligo pequeño (16-18\% del diametro) que en las vueltas internas aumenta con el crecimiento. En las últimas vueltas la concha muestra una tendencia a un enrollamiento excéntrico, llegando el ombligo a representar algo más del $25 \%$ del diámetro; región ventral ojival o ligeramente redondeada, y costillas muy gruesas, muy separadas y poco visibles, algo más marcadas en la región umbilical. En los especímenes obtenidos es difícil apreciar la ornamentación porque en general están muy desgastados.

Posición estratigráfica. Cronozona Oxynotum, parte medio-superior de la subcronozona Oxynotum.

Familia Cymbitidae Buckman, 1919

Género Cymbites Neumayr, 1878

Cymbites laevigatus (Sowerby, 1827)

(Fig. 11e)

1827 Ammonites laevigatus Sowerby, p. 135, Pl. 570, fig. 3.

1957 Cymbites laevigatus; Donovan, p. 413, figs. 1-8 (topotipos). 


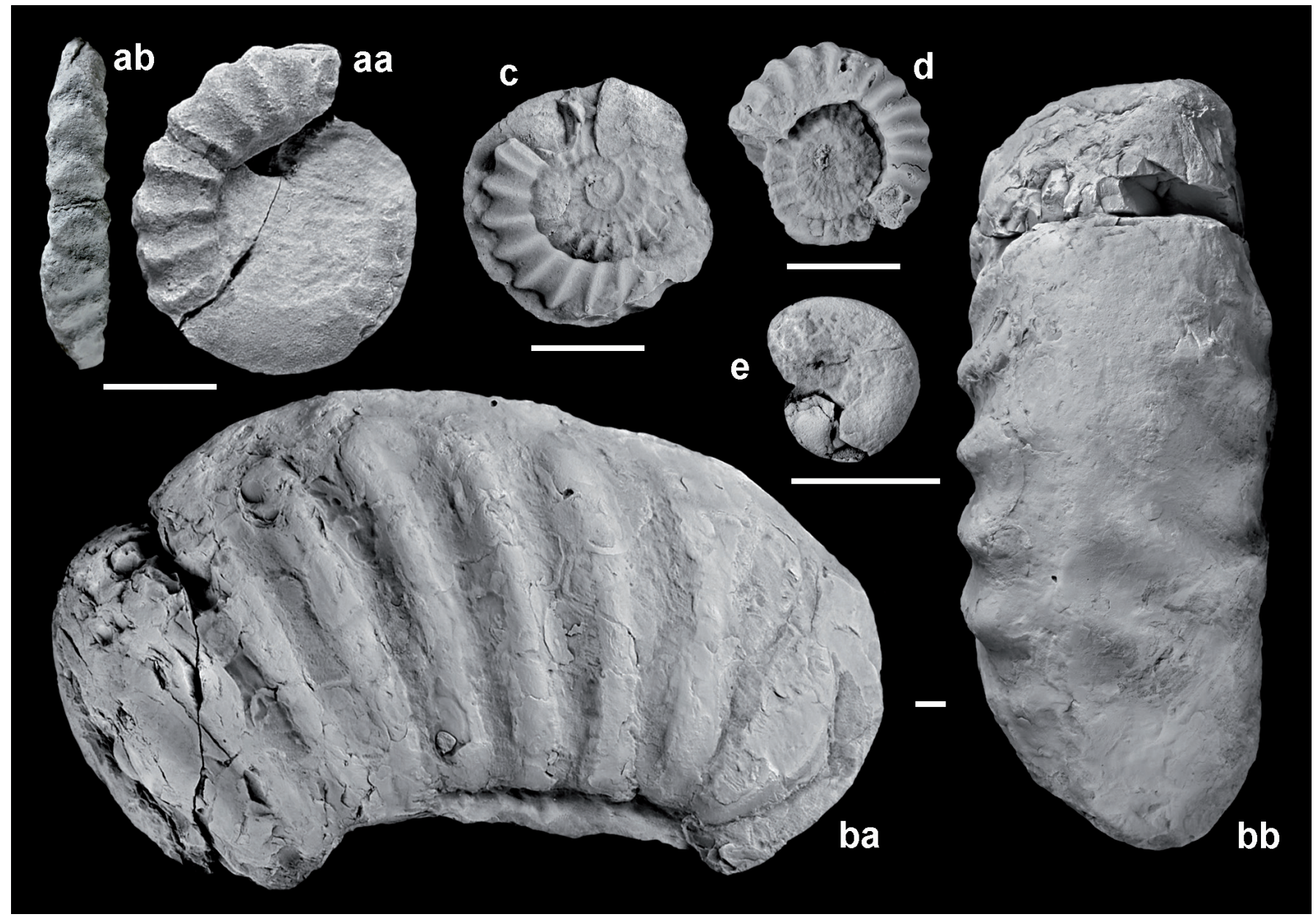

Figura 11. a) Xipheroceras cf. dudressieri, Subcronozona Obtusum, Peñarrubia, MUJA.4781. b) Xipheroceras. cf. ziphus, Subcronozona Obtusum, Peñarrubia, PÑ.125. c) Bifericeras cf. bifer, vaciado de látex, Subcronozona Oxynotum, Peñarrubia, PÑ.282. d) Promicroceras planicosta, Subcronozona Stellare, Peñarrubia, PÑ.146s. e) Cymbites laevigatus. Subcronozona Obtusum, Peñarrubia, PÑ.133. Escala gráfica $=1 \mathrm{~cm}$.

2002 Cymbites laevigatus; Howarth, p. 132, Pl. 5, fig. 6.

Material. PÑ.133, PÑ.145, PÑ.250, ER.16 (cf.).

Descripción. Formas muy pequeñas con vueltas internas involutas, que se van abriendo con el crecimiento (del 20\% del diámetro hasta el 35-40\%), globosas a ligeramente aplanadas, región ventral sin quilla, redondeada y típicamente lisas o con pliegues suaves.

Posición estratigráfica. Cronozona Obtusum, subcronozona Obtusuma a cronozona Oxynotum, parte inferior de la subcronozona Simpsoni.

Superfamilia Eoderocerataceae Spath, 1925

Familia Eoderoceratidae Spath, 1929

Subfamilia Eoderoceratinae Spath, 1929

Género Xipheroceras Buckman, 1911
Xipheroceras cf. dudressieri (d’Orbigny, 1845)

(Fig. 11a)

1845 Ammonites dudressieri d'Orbigny, p. 325, Pl 103, figs $1,2$.

1926 Xipheroceras dudressieri; Spath, p. 172, P1. 9, fig. 6 .

1994 Xipheroceras dudressieri; Fischer, p. 91, PI. 19, fig. 3.

2002 Xipheroceras dudressieri; Howarth, p. 132, PI. 5 , fig. 2.

Material. MUJA.4708, MUJA.4777, MUJA.4779, MUJA.4780, MUJA.4781.

Descripción. Se han incluido en el género Xipheroceras tres especímenes con el desarrollo ontogénico y los 


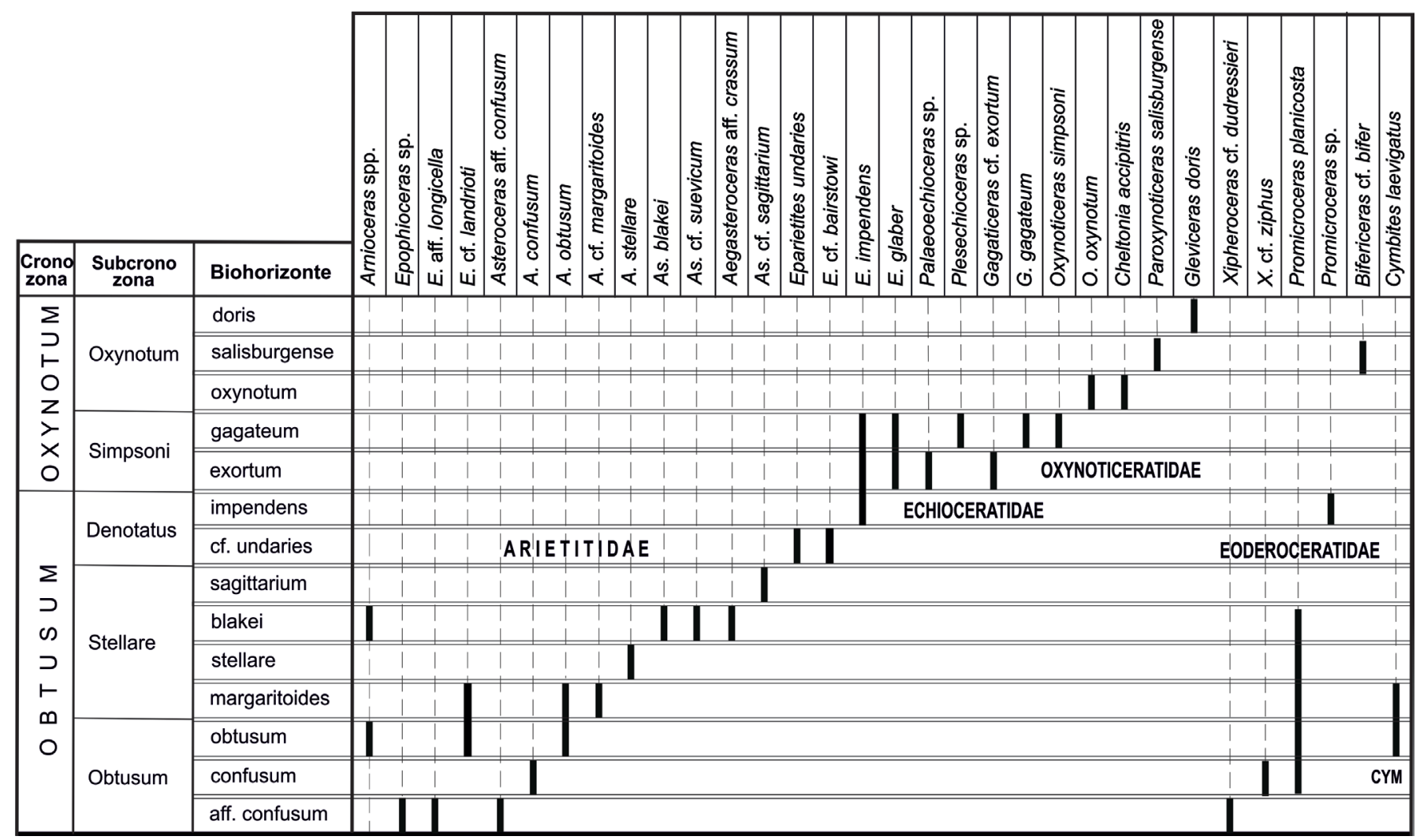

Figura 12. Subdivisiones cronoestratigráficas y biohorizontes de las cronozonas Obtusum y Oxynotum en la costa asturiana. CYM: Cymbitidae.

caracteres morfológicos próximos a los que muestra $X$. dudressieri, aunque los procedentes de PÑ tienen el ombligo algo menor, los tubérculos periumbilicales menos desarrollados y en ambos casos las costillas son un poco más retroversas y se suavizan ligeramente en la región ventral.

Posición estratigráfica. Cronozona Obtusum, parte inferior de la subcronozona Obtusum.

\section{Xipheroceras cf. ziphus (Zieten, 1830)}

(Fig. 11b)

1830 Ammonites ziphus Zieten, p. 6, Pl. 5, fig. 2 (holotipo).

1926 Xipheroceras ziphus; Buckman, P1. 732.

1976 Xipheroceras ziphus; Schlegelmilch, P1. 23, fig. 4.

2002 Xipheroceras ziphus; Howarth, p. 132, Pl. 5, fig. 5.

Material. PÑ.125.

Descripción. Xipheroceras de talla grande, evoluto, en el que no se aprecian los primeros estadios ontogenéticos; un núcleo con morfología próxima a la de Promicroceras y un estadio medio con una fila de tubérculos lateroventrales espinosos sobre costillas fuertes (cf. Corna \& Dommergues, 1988). Solo se aprecia el estadio tardío con una sección de la vuelta de subcircular a suboval, costillas relativamente bajas en las que apenas se individualizan los tubérculos ventrolaterales, que se difuminan al pasar sobre la región ventral que es casi lisa.

Posición estratigráfica. Cronozona Obtusum, subcronozona Obtusum.

Género Promicroceras Spath, 1925

Promicroceras planicosta (Sowerby, 1814)

(Fig. 11d)

1814 Ammonites planicosta Sowerby, p. 167, Pl. 73, fig. 5 (neotipo).

1925 Promicroceras planicosta; Spath, p. 299-302, fig. $8 \mathrm{f}$.

2002 Promicroceras planicosta; Howarth, p. 135, Pl. 5, fig. 4.

2010 Promicroceras aff. planicosta; Page, p. 229, Pl. 37, figs. 13, 14. 
2019 Promicroceras planicosta; Meister \& Schlögl, p. 54, fig. 40, 1, m, p-s.

Material. PÑ.148, PÑ.166, PÑ.198, PÑ.202, LLO.IS3.

Description. Concha de talla pequeña, evoluta, comprimida, vueltas internas lisas, las externas tienen costillas rectas y afiladas que se engrosan y aplanan en la región ventral.

Posición estratigráfica. Parte superior de la subcronozona Obtusum - subcronozona Stellare.

\section{Promicroceras sp.}

Material. PÑE.236, PÑ.239, PÑ.240.

Descripción. Tres especímenes de pequeña talla, mal conservados, en los que se aprecia la región ventral compatible con Promicroceras o con las primeras vueltas de Xipheroceras.

Posición estratigráfica. Cronozona Obtusum, parte inferior de la subcronozona Denotatus

Género Bifericeras Buckman 1913

Bifericeras cf. bifer (Quenstedt, 1845)

(Fig. 11c)

cf. 1845 Ammonites bifer Quenstedt, p. 83, P1. 4, fig. 14.

1976 Bifericeras bifer; Schlegelmilch, p. 58, Pl. 25, fig. 3 (neotipo).

1990 Bifericeras bifer; Hollingworth et al., p. 165, Pl. 2, figs. 1-12.

Material. PÑ.282, PÑ.290.

Description: Conchas de talla pequeña, evolutas, con ombligo de alrededor del $58 \%$, sección deprimida, primeras vueltas lisas y las externas con costillas afiladas y ligeramente retroversas en las que no se aprecian espinas bien desarrolladas, pero si engrosamientos umbilicales y ventrolaterales.

Posición estratigráfica. Cronozona Oxynotum, subcronozona Oxynotum.

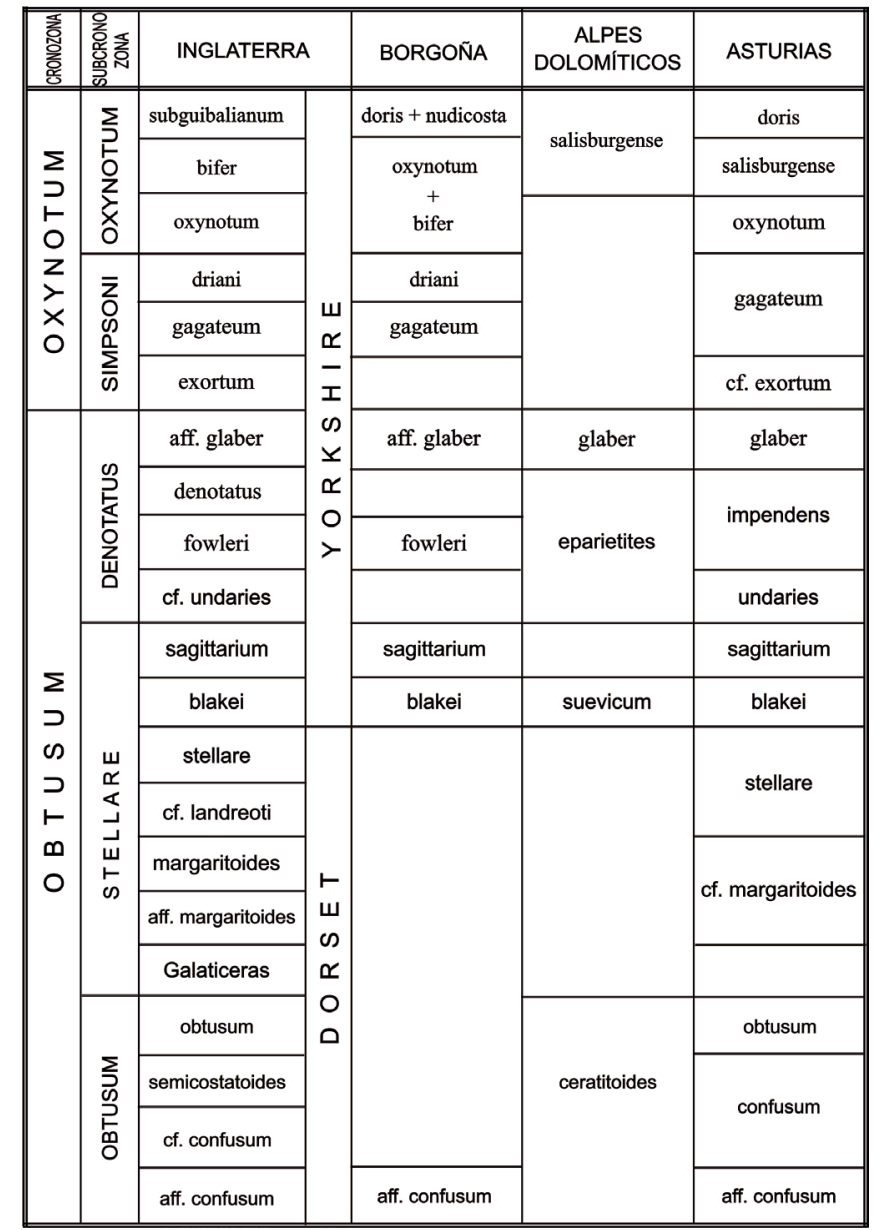

Figura 13. Correlación con otras áreas de las provincias NO Europea y Mediterránea.

\section{CRONOESTRATIGRAFÍA}

Las escalas cronoestratigráficas y bioestratigráficas de referencia, basadas en ammonoideos, que han sido utilizadas en este trabajo son las propuestas por Dean et al. (1961), Braga et al. (1984, 1985), Bloos (1985), Corna (1985, 1987), Corna \& Mouterde (1988), Corna et al. (1991, 1997a, 1997b), Page (1992, 2003), Dommergues (1993), Dommergues \& Meister (1992, 2017), Dommergues et al. (1994b)), Meister (1995), Blau \& Meister (2000), Blau et al. (2000), Hillebrandt (2002), Howarth (2002), Meister et al. (2005, 2006), Gèczy \& Meister (2007) y Guex et al. (2008), entre otras.

\subsection{Cronozona Obtusum Oppel, 1856}

El límite inferior de la cronozona Obtusum no ha podido ser señalado con precisión en ninguna de las localidades estudiadas. No se conocen ammonoideos in situ por debajo de los primeros Epophioceras y Asteroceras encontrados 
en PÑ, LLO y HU. Además, el registro existente en la parte basal de esta cronozona es muy escaso. Existen citas (Schultz, 1858) de Ammonites bisulcatus y Arieticeras, que fueron recogidas en la obra de Jiménez de Cisneros (1904) y que no han podido ser confirmadas en este trabajo. También se dispone de un espécimen de Coroniceras (Arietites) sp., procedente de la parte superior de la Fm. Gijón en el concejo de Colunga, que al haber sido recogido ex situ no permite situar la posición de la cronozona Semicostatum en la sucesión estratigráfica de este sector de la costa asturiana. Por otra parte, la ausencia de Caenisites del grupo de C. turneri (Sowerby) y de Microderoceras de las cronozonas Semicostatum y Turneri en los niveles previos a los que contienen los primeros Epophioceras y Asteroceras solo permite marcar la base de la cronozona Obtusum de forma aproximada. Sin embargo, el registro de ammonoideos obtenido en las secciones locales (Figs. 4-6) permite subdividir la cronozona Obtusum en tres subcronozonas (Obtusum, Stellare, Denotatus) e inferir la sucesión cronoestratigráfica que se detalla a continuación.

\subsubsection{Subcronozona Obtusum Oppel, 1856} (emend Dean et al., 1961)

Los primeros ammonoideos se han registrados por encima de los niveles con las últimas intercalaciones de materiales siliciclásticos, que han sido citados en el tránsito entre la cronozona Turneri y la cronozona Obtusum (por ejemplo, Robles et al., 1988, 2002; Braga et al., 1988). Se trata de Epophioceras aff. longicella y Epophioceras sp. en LLO y en HU, respectivamente. Estos Epophioceras ocupan una posición similar (base de la subcronozona Obtusum) a la que tienen los "grandes Epophioceras sp." citados por Corna et al. (1997a) en Francia, en la base del "Horizonte aff. confusum Page, 1992". Aunque de talla mayor, muestran un cierto parecido con los ejemplares de E. longicella procedentes de Djebel Oust en Túnez (Rakús \& Guex, 2002), que fueron atribuidos por Dommergues \& Meister (2017) a E. aff. longicella por tener una mayor densidad de costulación, en particular en las vueltas internas. Por encima, en PÑ se registra una sucesión de especies de Asteroceras (A. aff. confusum A. confusum - A. obtusum) que, de forma ocasional, están asociados a Xipheroceras en la parte inferior y media de la subcronozona Obtusum. En los niveles con $A$. confusum se han obtenido escasos especímenes de Promicroceras, Cymbites y Arnioceras. Este último género fue citado por Dubar \& Mouterde (1957) y encontrado ahora, ex situ, en las secciones HU y PÑ.

En esta subcronozona se ha obtenido la siguiente sucesión de ammonoideos: 1) Epophioceras aff. longicella; 2) Asteroceras aff. confusum, que puede estar asociado a Xipheroceras sp.; 3) Asteroceras confusum; 4) Arnioceras sp., Xipheroceras cf. ziphus, Promicroceras sp. y Cymbites laevigatus, aunque todos ellos son raros; 5) Asteroceras obtusum.

\subsubsection{Subcronozona Stellare Dumortier, 1867 (emend Dean et al., 1961)}

En la parte inferior persiste $A$. obtusum, que puede estar asociado a escasos Phylloceratida, Lytoceratida y Nautiloidea del género Cenoceras, así como a un Asteroceratinae involuto, de sección subtriangular, que recuerda al género Bagnolites Donovan, 1998. Luego siguen: 6) Asteroceras cf. margaritoides, asociado en algunos niveles a Promicroceras planicosta; 7) Epophioceras cf. landrioti, recogido ex situ por R. Mouterde \& L.C. Suárez Vega, en los años 70 del pasado siglo; Asteroceras stellare; 8) Asteroceras blakei, que en PÑ está asociado a Asteroceras cf. suevicum y en ER a Aegasteroceras sp. cf. crassum; 9) Arnioceras sp. (aff. arnouldi); 10) Aegasteroceras sagittarium.

\subsubsection{Subcronozona Denotatus Buckman, 1918} (emend Dean et al., 1961)

La base de esta subcronozona se marca con la primera aparición del género Eparietites, representado por la especie E. undaries. La sucesión obtenida en la sección $\mathrm{PN}$, que es la más completa, es la siguiente: 11) Eparietites undaries. Es probable que, de un nivel equivalente o muy próximo a él, proceda $E$. cf. bairstowi representado por un único ejemplar de gran talla (más de $45 \mathrm{~cm}$ ) en la sección de Playa de Vega; 12) Eparietites impendens, que es la especie más frecuente de este género y que puede estar asociada a raros Promicroceras sp.; 13) Eparietites glaber.

\subsection{Cronozona Oxynotum Oppel, 1856}

El límite inferior puede ser marcado con precisión en el área estudiada por la presencia de Gagaticeras, como G. cf. exortum y G. gagateum. De forma puntual, estas especies pueden estar asociadas a Palaeoechioceras sp. Además, el primer Oxynoticeras que se ha obtenido, O. simpsoni, procede de niveles algo más altos que los de G. gagateum, donde puede estar asociado a E. glaber. No obstante, teniendo en cuenta los datos obtenidos por otros autores en la sección de Robin Hood's Bay (Howarth, 2002), no se descarta que los primeros representantes de $O$. simpsoni pudieran ser más antiguos que los primeros Gagaticeras registrados en Asturias.

El registro de ammonoideos obtenido en las secciones locales (Figs. 4-6), permite subdividir la cronozona Oxynotum en dos subcronozonas (Simpsoni, Oxynotum) e inferir la sucesión cronoestratigráfica que se detalla a continuación. 


\subsubsection{Subcronozona Simpsoni J. Buckman, 1818}

El límite inferior se ha marcado con el primer registro del género Gagaticeras, que puede estar asociado a $O$. simpsoni. En esta subcronozona persisten Eparietites, como E. glaber, e incluso algunos especímenes con morfología muy próxima a la de E. impendens. La sucesión obtenida es la siguiente: 14) G. cf. exortum, junto con $E$. impendens y E. glaber; 15) G. gagateum, Palaeoechioceras sp., E. glaber y $O$. simpsoni; 16) O. simpsoni.

\subsubsection{Subcronozona Oxynotum Oppel, 1856}

El límite inferior se ha marcado con el primer registro de Oxynoticeras oxynotum, que está asociado a Cheltonia accipitris. La sucesión obtenida es la siguiente: 17) Oxynoticeras oxynotum, Cheltonia accipitris y "Plesechioceras" sp. 18) Bifericeras cf. bifer; 19) Paroxynoticeras salisburgense; 20) Gleviceras doris.

\section{BIOHORIZONTES DE AMMONOIDEOS} C A R A C T E R I Z A D O S E N E L INTERVALO CORRESPONDIENTE A LAS CRONOZONAS OBTUSUM Y OXYNOTUM

El registro obtenido de las 32 especies descritas en el capítulo de paleontología sistemática ha permitido caracterizar 15 biohorizontes de ammonoideos que pueden ser correlacionados con los de otras cuencas del O de Europa. En la Figura 12 se detalla la distribución cronoestratigráfica de las especies identificadas y se establece su relación con los biohorizontes reconocidos. Al tratarse de sistemas de clasificación diferentes, los utilizados para individualizar unidades cronoestratigráficas (cronozonas y subcronozonas) y bioestratigráficas (biohorizontes) los límites entre ambos tipos de unidades no tienen porqué coincidir.

Los biohorizontes de la cronozona Obtusum se han establecido teniendo en cuenta la evolución de las especies de Arietitidae, Asteroceratinae de los géneros Asteroceras (A. aff. confusum, A. confusum, A. obtusum, A. cf. margaritoides, A. stellare, A. blakei) y Aegasteroceras (A. aff. crassum, A. sagittarium), durante el intervalo correspondiente a las subcronozonas Obtusum y Stellare y de Asteroceratinae del género Eparietites (E. undaries, E. cf. bairstowi, E. impendens) en el intervalo correspondiente a la subcronozona Denotatus.

Los biohorizontes de la Zona Oxynotum se han establecido a partir de la sucesión de especies de Echioceratidae del género Gagaticeras ( $G$. cf. exortum, G. gagateum), que están asociadas a Palaeoechioceras sp. y Oxynoticeras simpsoni en el intervalo correspondiente a la subcronozona Simpsoni y de Oxynoticeratidae de los géneros Oxynoticeras (O. oxynotum) y Cheltonia (C. accipitris), Paroxynoticeras (P. salisburgense) y Gleviceras $(G$. doris), en el intervalo correspondiente a la subcronozona Oxynotum.

\section{DISCUSIÓN}

\subsection{Correlación con otras cuencas de la parte occidental del Tetis}

La sucesión de los biohorizontes reconocidos en las cronozonas Obtusum y Oxynotum de Asturias (Fig. 13), tiene notable similitud con las descritas en el S de Inglaterra, en Dorset (Page, 1992, 2003) y en el NE de Inglaterra, en Yorkshire (Howarth, 2002). También es comparable con las descritas en Francia, en Borgoña y en el Subbriançonaise (Dommergues, 1987, 1993; Dommergues et al., 1994a, 2005; Blau \& Meister, 2000), así como en otras localidades del NO de la Europa continental. Sin embargo, en la costa asturiana se registran algunos elementos que son más propios de áreas mediterráneas, como $A$. cf. suevicum, Eparietites glaber y $P$. salisburgense, que se sitúan respectivamente en la parte superior de la subcronozona Stellare, en el tránsito entre las subcronozonas Denotatus y Simpsoni, y en la parte media-superior de la subcronozona Oxynotum (Blau, 1998), coincidiendo con intervalos de profundización relativa.

En la Península Ibérica, en la Cuenca Vasco-Cantábrica, es, sin duda, donde la sucesión de facies y las asociaciones de ammonoideos obtenidas son más parecidas a las de la Cuenca Asturiana. En ambos casos, sobre un tramo de areniscas y microconglomerados con estructuras de tracción, bioturbación que puede llegar a ser importante, y restos fósiles frecuentes de bivalvos, gasterópodos, crinoideos, equinoideos, corales, briozoos, ostrácodos y foraminíferos (ver Braga et al., 1988), se han registrado Asteroceras spp., Asteroceras gr. stellare, Eparietites sp. y raros Epophioceras, probablemente del grupo de $E$. landrioti (d'Orbigny). Recientemente, se han obtenido dos especímenes de Asteroceras del grupo de $A$. confusum a $4,8 \mathrm{~m}$ y $5,40 \mathrm{~m}$ por encima del nivel H32 (con granos de cuarzo en proporciones superiores al $5 \%$ ), en una posición análoga a la que esta especie muestra en Asturias. En la cronozona Oxynotum existen varios elementos de correlación, como Gagaticeras, Palaeoechioceras, Oxynoticeras-Cheltonia y Gleviceras. En otras cuencas del NE de España, como las pirenaicas y catalanas, y de Baleares el registro de ammonoideos de las cronozonas Obtusum y Oxynotum es, de momento, inexistente (Cadillac et al., 1981; Fauré, 2002; Goy, 2002; Gómez \& 
Goy, 2004). En la Cordillera Ibérica solo los niveles con Oxynoticeras oxynotum y Cheltonia accipitris, citados por Comas-Rengifo (1982), pueden ser correlacionados con los que incluyen las mismas especies en la cronozona Oxynotum de Asturias.

En la Cuenca Lusitánica casi no existen elementos de correlación con Asturias en la cronozona Obtusum, ya que, con excepción de muy pocos especímenes de Asteroceras sp., solo se han registrado especies de géneros endémicos (Mouterde \& Rocha, 1981; Dommergues \& Mouterde, 1987; Dommergues et al., 2004), como Ptycharietites (Spath, 1925), especie tipo: Arietites (Asteroceras) ptychogenos Pompeckj, 1897, y Epophioceroides (Dommergues et al., 2010), especie tipo: Epophioceroides apertus Dommergues et al., 2010. Sin embargo, en la cronozona Oxynotum, coincidiendo con un episodio de máxima inundación relativa, se han registrado Oxynoceratidae (O. gr. oxynotum, $C$. cf. accipitris), Eoderoceratidae (B. bifer) y Echioceratidae ( $P$. cf. platypleura), asociación de especies que también se conoce en Asturias en la subcronozona Oxynotum (ComasRengifo et al., 2013; Duarte et al., 2014).

En la Cordillera Bética, situada en una posición que corresponde netamente a la Provincia Mediterránea, solo se pueden correlacionar con fiabilidad los niveles de la "asociación 5" de Braga et al. (1985) en Sierra Harana, con E. landrioti, A. cf. suevicum, y Arnioceras, como A. pluriplicatum y $A$. dimorphum. Esta asociación, con alta probabilidad corresponde a la subcronozona Stellare. Más difícil parece la correlación con otras secciones, como las de Alhama de Granada y Gaucín (ver Braga et al., 1984).

\subsection{Paleobiogeografía}

Al comienzo del Sinemuriense superior, las cuencas situadas en la Cordillera Cantábrica (Cuenca Asturiana y Cuenca Vasco-Cantábrica) formaban parte la Provincia del NO de Europa de ammonoideos. Se situaban cerca y estaban bien comunicadas con Dorset, en el S de Inglaterra (Page, 1992, 1994), e incluso con otras áreas del centro y del NE de Inglaterra, como Gloucestershire y Yorkshire (Howarth, 2002; Page, 2003), así como con algunas áreas epicontinentales de Francia y del SO de Alemania, como Borgoña, el Subbriançonnais, las Causses, Württemberg, etc (Dommergues, 1993; Meister, 1995; Dommergues et al., 1997; Blau, 1998; entre otros).

Por el contrario, las conexiones con áreas alpinas, como Cordillera Bética, Apeninos, Alpes Dolomíticos, Alpes Austriacos, Cárpatos, etc., presumiblemente eran peores y solo se han obtenido unos pocos elementos que pueden ser utilizados para establecer una correlación fiable, como ya se ha expuesto anteriormente (Braga et al., 1985; Dommergues et al., 1994a; 2005; Blau \& Meister, 2000; Meister \& Friebe, 2003; Meister et al., 2006; Meister
\& Schlög, 2019). Por otra parte, sorprende el notable aislamiento existente entre el área investigada y la parte $\mathrm{N}$ de la Cuenca Lusitánica. Hasta el momento, no se dispone de datos precisos sobre cuáles han sido las causas o las barreras efectivas, para los ammonoideos, que impidieron circular a los especímenes de la cronozona Obtusum por las plataformas que presuntamente unían Asturias y la Cuenca Lusitánica. Máxime cuando las facies que muestran las unidades litoestratigráficas reconocidas son notablemente parecidas, y otros grupos de invertebrados, como los braquiópodos, pudieron superar, en algunos casos, dichas barreras.

\section{CONCLUSIONES}

La sucesión de las rocas carbonáticas del Sinemuriense superior en la costa centro-oriental asturiana se conoce bien en los aspectos litoestratigráficos y biosedimentarios, pudiéndose apreciar los principales eventos sedimentarios, de forma muy precisa, entre Gijón y Ribadesella. Aunque los ammonoideos muestran un registro relativamente pobre en la mayor parte de las cronozonas Obtusum y Oxynotum, se ha podido mejorar notablemente el conocimiento de la biocronoestratigrafía del intervalo temporal estudiado. $\mathrm{Si}$ se exceptúa el límite inferior de la cronozona Obtusum, todas las unidades cronoestratigráficas (cronozonas y subcronozonas de la escala estándar) han podido ser caracterizadas con bastante precisión, de forma que la sucesión que se describe, especialmente en el sector occidental del área estudiada (Peñarrubia), es la más completa y mejor datada del Sinemuriense superior español en el intervalo considerado.

En la cronozona Obtusum (subcronozonas Obtusum y Stellare) se suceden en el tiempo seis especies de Asteroceras (aff. confusum, confusum, obtusum, cf. margaritoides, stellare, blakei) y dos de Aegasteroceras (cf. crassum, sagittarium), que de forma puntual pueden estar asociadas a escasos Epophioceras, Xipheroceras, Promicroceras y Cymbites. La subcronozona Denotatus se ha caracterizado por la existencia de cuatro especies de Eparietites (undaries y cf. bairstowi en la parte inferior, seguidas de impendens y glaber que se solapan parcialmente en el tiempo), siendo raros otros grupos de ammonoideos. En la cronozona Oxynotum se registran Echioceratidae (Palaeoechioceras, Gagaticeras) y Oxynoticeratidae (O. simpsoni en la subcronozona Simpsoni y $O$. oxynotum y $C$. accipitris en la subcronozona Oxynotum). En la parte media y superior de esta subcronozona, se registran asimismo Paroxynoticeras y Gleviceras, respectivamente.

En el aspecto paleobiogeográfico, la sucesión obtenida es típica de la Provincia NO Europea con la inclusión de algunos elementos que son más habituales en la Provincia 
Mediterránea en la parte media y superior de la cronozona Obtusum (A. cf. suevicum, E. glaber) y en la parte media de la cronozona Oxynotum (P. salisburgense).

\section{AGRADECIMIENTOS}

A los Dres. Juan Carlos Braga y José Sandoval agradecemos sus comentarios y sugerencias, que nos han permitido mejorar el manuscrito original, y a Carlos Alonso Recio (Área de Paleontología de la Facultad de Ciencias Geológicas de la UCM) su excelente trabajo fotográfico. Esta investigación ha sido financiada por el Proyecto CGL201566604-R (MINECO), por el Grupo de Investigación UCM 910431, Procesos Bióticos Mesozoicos y por la Sociedad Pública de Gestión y Promoción Turística y Cultural del Principado de Asturias.

\section{REFERENCIAS}

Aurell, M., Robles, S., Bádenas, B., Rosales, I., Quesada, S., Meléndez, G. \& García-Ramos, J.C. 2003. Transgressiveregressive cycles and Jurassic palaeogeography of northeast Iberia. Sedimentary Geology, 162, 239-271; doi: 10.1016/S0037-0738(03)00154-4.

Bádenas, B., Aurell, M. \& Bosence, D. 2010a. Continuity and facies heterogenities of shallow carbonate ramp cycles (Sinemurian, Lower Jurassic, North-east Spain). Sedimentology, 57, 1021-1048; doi: 10.1111/j.13653091.2009.01129.x.

Bádenas, B., Aurell, M., García-Ramos, J.C. \& Piñuela, L. 2010b. Ciclos de somerización del Sinemuriense superior. In: Las Sucesiones Margo-Calcáreas Marinas del Jurásico Inferior y las Series Fluviales del Jurásico Superior. Acantilados de Playa de Vega (Ribadesella) (coord. García-Ramos, J.C.). Museo de Jurásico de Asturias, Colunga, 19-20.

Barth, G., Pieńkowski, G., Zimmermann, J., Franz, M. \& Kuhlmann, G. 2018. Palaeogeographical evolution of the Lower Jurassic: high-resolution biostratigraphy and sequence stratigraphy in the Central European Basin. In: Mesozoic Resource Potential in the Southern Permian Basin (eds. Kilhams, B., Kukla, P.A., Mazur, S., Mckie, T., Mijnlieff, H.F. \& Van Ojik, K). Geological Society, London, Special Publications, 469, 341-369; doi: 10.1144/ SP469.8.

Bernad, J. \& Martínez, G. 1996. Revisión de los Ammonoideos del Lías español depositados en el Museo Geominero (1TGE, Madrid). Boletín Geológico y Minero, 107, 103-124.

Blake, J.F. 1876. Class Cephalopoda. In: The Yorkshire Lias (eds. Tate, R. \& Blake, J.F.). John Van Voorst London. p. 261-330.
Blau, J. 1998. Monographie der Ammoniten des Obersinemuriums (Lotharingium, Lias) der Lienzer Dolomiten (Österreich): Biostratigraphie, systematik und paläobiogeographie. Revue de Paléobiologie, 17, 177-285.

Blau, J. \& Meister, C. 2000. Upper Sinemurian ammonite succesions based on 41 faunal horizons: an attempt at worldwide correlation. GeoResearch Forum, 6, 3-12.

Blau, J., Meister, C., Ebel, R. \& Schlatter, R. 2000. Upper Sinemurian and Lower Pliensbachian ammonite faunas from Herford-Diebrock area (NE Germany). Paläontologische Zeitschrift, 74, 259-280. doi: 10.1007/BF02988101

Bloos, G. 1985. Les couches basales du Sinemurien - une révisión stratigraphique. Les Cahiers de l'Institute Catholique de Lyon, 14, 59-68.

Bosence, D., Procter, E., Aurell, M., Bel kahla, A., BoudagherFadel, M., Casaglia, F., Cirilli, S., Mehdie, M., Nieto, L., Rey, J., Scherreiks, R., Soussi, M. \& Waltham, D. 2009. A dominant tectonic signal in high-frequency, peritidal carbonate cycles? A regional analysis of Liassic platforms from western Tethys. Journal of Sedimentary Research, 79, 389-415; doi: 10.2110/jsr.2009.038.

Braga, J.C., Martín-Algarra, A. \& Rivas, P. 1984. Biostratigraphic sketch of the Lower Lias of the Betic cordilleras. In: International Symposium on Jurasic Stratigraphy (eds. Michelsen, O. \& Zeiss, A.). Geological Survey of Denmark Copenhagen, I, 177-190.

Braga, J.C., Martín-Algarra, A. \& Rivas, P. 1985. Ammonites du Lias inférieur (Sinémurien-Lotharingien) de Sierra Harana (Cordillères Bètiques, Espagne). Cahiers de l'Université Catholique de Lyon, 14, 85-101.

Braga, J.C., Comas-Rengifo, M.J., Goy, A., Rivas, P. \& Yébenes, A. 1988. El Lías inferior y medio en la Zona Central de la Cuenca Vasco-Cantábrica (Camino, Santander). Ciencias de la Tierra, 11, 17-45.

Buckman, J. 1844. In: R.I. Murchison. 1844. Outline of the Geology of the Neighbourhood of Cheltenham (eds. Strickland, H.E. \& Buckman, J.). John Murray London.

Buckman, S.S. 1904. Ammonites colesi, Ammonites cultellus, Ammonites halecis, Ammonites accipitris, Ammonites bodleyi, Ammonites fowleri, Ammonites sulcatus, Ammonites sowerbii. Palaeontologia Universalis, Centuria 1. Congres Géologique International. Laval. Fiche 2-27, $36,37,39,52$.

Buckman, S.S. 1909-1930. Yorkshire Type Ammonites, Vol. 1-2. Type Ammonites, Vol. 3-7. Wheldon \& Wesley. London.

Cadillac, H., Canerot, J. \& Fauré, Ph. 1981. The Jurassique inférieur aux confins des Ibérides et des Catalánides (Espagne). Estudios geológicos, 37, 187-198.

Comas-Rengifo, M.J. 1982. El Pliensbachiense de la Cordillera Ibérica. Ph.D. Thesis, Facultad de Ciencias Geológicas, UCM, 19/1985.

Comas-Rengifo, M.J. \& Goy, A. 2010. Caracterización biocronoestratigráfica del Sinemuriense Superior y el Pliensbachiense entre los afloramientos de Playa de Vega y de Lastres (Asturias). In: Las Sucesiones MargoCalcáreas Marinas del Jurásico Inferior y las Series Fluviales del Jurásico Superior. Acantilados de Playa de 
Vega (Ribadesella) (coord. García-Ramos, J.C.). Museo de Jurásico de Asturias, Colunga, p. 9-18.

Comas-Rengifo, M.J., García-Martínez, J.C. \& Goy, A. 2010. Sinemuriense superior en Rodiles (Asturias): Biocronoestratigrafía y biohorizontes de ammonoideos. In: Comunicaciones V Congreso del Jurásico de España (eds. Ruiz-Omeñaca, J.L., Piñuela, L. \& García-Ramos, J.C.). Museo de Jurásico de Asturias, Colunga, p. 3-9.

Comas-Rengifo, M.J., Duarte, L.V., Goy, A., Paredes, R. \& Silva, R.L. 2013. O Sinemuriano superior (cronozonas Oxynotum e Raricostatum) na região de S. Pedro de Moel (Bacia Lusitânica, Portugal. Comunicações Geológicas, 100, 15-19.

Corna, M. 1985. Le Lias du Jura meridional Paléontologie biostratigraphique du Sinémurien. Approche paléoécologique. Thèse $3^{\mathrm{e}}$ cycle Université Lyon, $255 \mathrm{pp}$.

Corna, M. 1987. Les horizonts Sinémuriens du Calcaire à Gryphées du Jura meridional français (Zone à Conybeari - Zone à Obtusum. Geobios, 20, 531-536; doi: 10.1016/ S0016-6995(87)80085-2.

Corna, M. \& Dommergues, J.-L., 1988. Xipheroceras trimodum (Dumortier) (Ammonitina, Lias): précisions stratigraphiques et paléontologiques. Comptes Rendus de l'Acadgmie des Sciences de Paris, 2, 307, 1465-1471.

Corna, M. \& Mouterde, R. 1988. Le Sinémurien de Semur (France): essai de biozonation pour le Sinémurien inférieur et le Lotharingien inférieur du stratotype et du Jura méridional. In: 2nd International Symposium on Jurassic Stratigraphy (eds. Rocha, R.B. \& Soares, A.F.). Lisboa, p. 101-107.

Corna, M., Dommergues, J.-L., Meister, C. \& Mouterde, R. 1991. Sinémurien. In: $3^{\text {rd }}$ International Symposium on Jurassic Stratigraphy. Poitiers. Résumés, p. 125.

Corna, M., Dommergues, J.-L., Meister, C. \& Mouterde, R. 1997a. Sinémurien. In: Biostratigraphie du Jurassique Ouest-Européen et Méditerranéen: Zonations Parallèles et Distribution des Invertébrés et Microfossiles (coord. Cariou, E. \& Hantzpergue, P.). Bulletin des Centres de Recherche Exploration-Production Elf-Aquitaine, Mémoire, 17, 9-14.

Corna, M., Dommergues, J.-L., Meister, C. \& Page, K.N. 1997b. Les ammonites du Jurassique inférieur (Hettangien, Sinémurien et Pliensbachian) au nord du massif des Ecrins (Oisans, Alpes occidentales françaises). Revue de Paléobiologie, 16, 321-409.

D'Orbigny, A. 1842-1851. Paléontologie Française. Terrains Oolitiques o Juras Paris siques. I. Céphalopodes.

De Graciansky, P.C., Jacquin, T. \& Hesselbo, S.P. 1998. The Ligurian Cycle: an overview of Lower Jurassic $2^{\text {nd }}$ order transgressive-regressive cycles in Western Europe. In: Mesozoic and Cenozoic Sequence Stratigraphy of European Basins (eds. Graciansky, P.C., Hardenbol, J. $\&$ Vail, P.R). Society of Economic Paleontologists and Mineralogists, 60, 468-479. doi: 10.2110/pec.98.02.0467

Dean, W.T., Donovan D.T. \& Howarth, M.K. 1961. The Liassic ammonite zones and subzones of the North-West European Province. Bulletin of the British Museum of (Natural History), Geology Series, 4, 435-505.
Dommergues, J.-L. 1987. L'évolution chez les Ammonitina du Lias moyen (Carixien, Domérien basal) en Europe occidentale. Documents des Laboratoires de Géologie de Lyon, 98.

Dommergues, J.-L. 1993. Les ammonites du Sinémurien supérieur de Bourgogne (France): Biostratigraphie et remarques paléontologiques. Revue de Paléobiologie, 12, 67-173.

Dommergues, J.-L. \& Meister, C. 1992. Late Sinemurian and early Carixian ammonites in Europe with cladistic analysis of sutura characters. Neues Jahrbuch fur geologie und Paläontology Abhandlungen, 185, 211-237.

Dommergues, J.-L. \& Meister, C. 2017. Ammonites du Jurassique inférieur (Hettangien, Sinémurien, Pliensbachien) d'Afrique du Nord (Algérie, Maroc et Tunisie). Atlas d'identification des especès. Revue de Paléobiologie, 36, 189-367; doi: 10.5281/zenodo.18905.

Dommergues, J.-L. \& Mouterde, R. 1987. The endemic trends of Liassic ammonite faunas of Portugal as the results of the opening up of a narrow epicontinental basin. Palaeogeography, Palaeoclimatology, Palaeoecology, 58, 129-137; doi: 10.1016/0031-0182(87)90056-3.

Dommergues, J.-L., Ferreti, A. \& Meister, C. 1994a. Les faunes d'ammonites du Sinémurien de l'Apènnin Central (Marches et Toscane, Italie). Bollettino della Società Paleontologica Italiana, 33, 13-42.

Dommergues, J.-L., Page, K.N. \& Meister, C. 1994b. A detailed correlation of Upper Sinemurian (Lower Jurassic) ammonite biohorizonts between Burgundy (France) and Britain. Newsletters on Stratigraphy, 30, 61-73.

Dommergues, J.-L., Meister, C. \& Böhm, F. 1995. New data on Austroalpine Liassic ammonites from the Adnet Quarries and adjacent areas (Oberösterreich, Northern Calcareous Alps). Jahrbuch der Geologischen Bundesanstalt, 138, 161-205.

Dommergues, J.-L., Meister, C. \& Mouterde, R. 1997. Pliensbachien. In: Biostratigraphie du Jurassique OuestEuropéen et Méditerranéen: Zonations Parallèles et Distribution des Invertébrés et Microfossiles (coord. Cariou, E. \& Hantzpergue, P.). Bulletin des Centres de Recherche Exploration-Production Elf-Aquitaine, 17, 15-23.

Dommergues, J.-L., Meister, C., Neige, P. \& Rocha, R.B. 2004. Endemic Sinemurian (Early Jurassic) ammonites from the Lusitanian Basin (Portugal). Revue de Paléobiologie, 23, 529-549.

Dommergues, J.-L., Forest-Bize, N., Gely, J.-P. \& Loreau, J.-P. 2005. Les faunes d'ammonites du Sinémurien (Jurassique inferieur) du Perron des Encombres (Alpes occidentales françaises. Zone subbriannçonaise entre Arc et Isère). Revue de Paléobiologie, 24, 673-696.

Dommergues J.-L., Meister, C. \& Rocha, R.B. 2010. The Sinemurian ammonites of the Lusitanian Basin (Portugal): an example of complex endemic evolution. Palaeodiversity, 3, 59-87.

Donovan, D.T. 1957. Notes on the species Cymbites laevigatus (J. de C. Sowerby) and on the genus Cymbites Neumayr. Geological Magazine, 94, 413-420. 
Donovan, D.T. 1998. A new ammonite genus from the Lower Jurassic (Upper Sinemurian) of Dorset, England. Palaeontology, 41, 993-999.

Donovan, D.T. \& Forsey, G.F. 1973. Systematics of Lower Liasssic Ammonitina. The University of Kansas Paleontological Contributions, 64.

Duarte, L.V., Comas-Rengifo, M.J., Silva, R.L., Paredes, R. \& Goy, A. 2014. Carbon isotope, stratigraphy and ammonite biochronostratigraphy across the Sinemurian-Pliensbachian boundary in the western Iberian margin. Bulletin of Geosciences, 89, 719-736. doi: 10.3140/bull.geosci.1476

Dubar, G. 1925a. Sur les formations du Lias et du Jurassique supérieur dans les Asturies. Comptes Rendues hebdomadaires des Séances de l'Académie des Sciences, 180, 215-217.

Dubar, G. 1925b. Étude sur le Lias des Pyrénées françaises. Mémoire de la Societé Géologique du Nord, 9.

Dubar, G. \& Mouterde, R. 1957. Précisions sur le Lias des Asturies. Comptes Rendues hebdomadaires des Séances de l'Académie des Sciences, 244, 234-236.

Dubar, G., Mouterde, R., Virgili, C. \& Suárez-Vega, L.C. 1971. El Jurásico de Asturias (Norte de España). Cuadernos de Geología Ibérica, 2, 561-580.

Dumortier, E. 1867. Études Paléontologiques sur les Dépôts Jurassiques du Bassin du Rhône: Deuxième Partie. Lias Inférieur. Savy, Paris.

Edmunds, M.J. Whicher, J., Langham, P. \& Chandler, R.B. 2016. A systematic account of the ammonite faunas of the Obtusum Zone (Sinemurian Stage, Lower Jurassic) from Marston Magna, Somerset, UK. Proceedings of the Geologists' Association, 127, 146-171; doi: 10.1016/j. pgeola.2016.01.006.

Fauré, P. 2002. Le Lias des Pyrénées. Strata, Serie 2, 39, 1-761.

Fischer, J.-C. 1994. Révision Critique de la Paléontologie Française d'Alcide d'Orbigny, vol. 1. Céphalopodes. Jurassiques. Paris.

García-Martínez, J.C. 2001. El Sinemuriense Superior (Lotharingiense) de Rodiles (Asturias). M.Sc. Thesis, Universidad Complutense de Madrid (unpublished).

García-Ramos, J.C. \& Gutiérrez-Claverol, M. 1995a. La cobertera mesozoico-terciaria. In: Geología de Asturias (eds. Aramburu, C. \& Bastida, F.). Editorial Trea, Gijón, 81-94.

García-Ramos, J.C. \& Gutiérrez-Claverol, M. 1995b. La geología de la franja costera oriental de Asturias y la depresión prelitoral de Oviedo-Cangas de Onís. In: Geología de Asturias (eds. Aramburu, C. \& Bastida, F.). Editorial Trea, Gijón, 247-258.

García-Ramos, J.C., Valenzuela, M. \& Suárez de Centi, C. 1989. Estructuras de deformación asociadas a tempestitas: ejemplos en series siliciclásticas y carbonatadas someras del Paleozoico y Jurásico de Asturias. Trabajos de Geología, 18, 65-76.

García-Ramos, J.C., Valenzuela, M. \& Suárez de Centi, C. (eds.) 1992. Guía de Campo. Rampa Carbonatada del Jurásico de Asturias. Reunión Monográfica Sobre Biosedimentación. Departamento de Geología, Universidad de Oviedo y Sociedad Geológica de España.
García-Ramos, J.C., Piñuela, L. \& Aramburu, C. 2010. Introducción al Jurásico de Asturias. In: Las Sucesiones Margo-Calcáreas Marinas del Jurásico Inferior y las Series Fluviales del Jurásico Superior. Acantilados de Playa de Vega (Ribadesella) (coord. García-Ramos, J.C.). Museo del Jurásico de Asturias, Colunga, 1-8.

García-Ramos, J.C., Piñuela, L. \& Rodríguez-Tovar, J.F. (coords.) 2011. Post-Workshop Field Trip Guide of the XI International Ichnofabric Workshop. Museo del Jurásico de Asturias (MUJA), Colunga, Spain.

Gèczy, B. \& Meister, C. 2007. Les ammonites du Sinémurien et du Pliensbachien inférieur de la montagne du Bakony (Hongrie). Revue de Paléobiologie, 26, 137-305.

Getty, T.A. 1973. Revision of the generic classification of the Family Echioceratidae (Cephalopoda, Ammonoidea) (Lower Jurassic). The University of Kansas Paleontological Contributions, 63.

Gómez, J.J. \& Goy, A. 2004. Jurásico Inferior de las cordilleras Ibérica y Costero-Catalana. In: Geología de España (ed. Vera, J.A.). SGE-IGME, Madrid, p. 495-500.

Gómez, J.J. \& Goy, A. 2005. Late Triassic and Early Jurassic palaeogeographic evolution and depositional cycles of the Western Tethys Iberian platforms system (Eastern Spain) Palaeogeograpy, Palaeoclimatology, Palaeoecology, 222, 77-94; doi: 10.1016/j.palaeo.2005.03.01

Goy, A. 2002. Lower Jurassic: Balearic Islands. In: The Geology of Spain (eds. Gibbons, W. \& Moreno, T.). The Geological Society, London, 241-244.

Guérin-Franiatte, S. 1966. Ammonites du Lias inférieur de France, Psilocerataceae: Arietitidae. Éditions du Centre National de la Recherche Scientifique, Tome 1. París.

Guex, J., Rakus, M., Morard, A., Quatier-la-Tente, M. 2008. Ammonites sinémuriennes du Haut-Atlas marocain. Mémoires de Géologie (Lausanne), 47, 1-82.

Haq, B.U., Hardenbol, J. \& Vail, P. 1988. Mesozoic and Cenozoic chronostratigraphy and eustatic cycles. In: Sea Level Changes: An Integrated Approach (eds. Wilgus, C.K., Hastings, B.S., Kendall, C.G.St.C., Posamentier, H.W., Ross, C.A. \& Van Wagoner, J.C.). SEPM, Special Publication, 42, 71-108.

Hauer, F.R. von. 1856. Über die Cephalopoden aus dem Lias der nordöstlichen Alpen. Denkschriften der MathematischNaturwissenschaftlichen Classe der Kaiserlichen Akademie der Wissenschaften, 11.

Hesselbo, S.P. 2008. Sequence stratigraphy and inferred relative sea-level change from the onshore British Jurassic. Proceedings of the Geologists 'Association, 119, 1, 19-34. doi: 10.1016/S0016-7878(59)80069-9

Hesselbo, S.P. \& Jenkyns, H.C. 1998. British Lower Jurassic sequence stratigraphic. In: Mesozoic and Cenozoic Sequence Stratigraphy of European Basin (eds. de Graciansky, P.C., Hardenbol, J., Jacquin, T. \& Vail, P.R.). SEPM Special Publications, 60, 561-581. doi: 10.2110/ pec.98.02.0561

Hillebrandt, A. von. 1981. Faunas de ammonites de Liásico inferior y medio (Hettangiano hasta Pliensbachiano) de América del Sur (excluyendo Argentina). In: Cuencas Sedimentarias del Jurásico y Cretácico de América 
del Sur, vol. 2 (eds. Volkheimer, W. \&. Musacchio, A.). Comité Sudamericano del Jurásico y Cretácico al Congreso Latinamericano de Paleontología, Buenos Aires, 499-538.

Hillebrandt, A. von 2002. Ammoniten aus dem oberen Sinemurium von Südamerika. Revue de Paléobiologie, 21, 35-147.

Hollingworth, N.T.J., Ward, D.J., Simms, M.J. \& Clothier, P. 1990. A temporary exposure of Lower Lias (Late Sinemurian) at Dimmer Camp, Castle Cary, Somerset, south-west England. Mesozoic Research, 2, 163-180.

Howarth, M.K. 1962. The Yorkshire type ammonites and nautiloids of Young \& Bird, Phillips and Martin Simpson. Palaeontology, 5, 93-127.

Howarth, M.K. 2002. The Lower Lias of Robin Hood's Bay, Yorkshire, and the work of Leslie Bairstow. Bulletin of the Natural History Museum, 58, 81-152; doi: 10.1017/ S0968046202000037.

Hyatt, A. 1867. The fossil cephalopods of the Museum of Comparative Zoology. Bulletin of the Museum of Comparative Zoology, 5, 71-102.

Hyatt, A. 1875. Remarks on two genera of Ammonites, Agassiceras and Oxynoticeras. Proceedings of the Boston Society of Natural History, 17, 225-235.

Jiménez de Cisneros, D. 1904. Datos para el estudio del sistema liásico de Asturias. Boletín de la Real Sociedad Española de Historia Natural, 4, 298-305.

Mallada, L. 1885. Sinopsis de las especies fósiles que se han encontrado en España. T. II. Terreno Mesozoico (Sistemas Triásico y Jurásico). Boletín de la Comisión del Mapa Geológico de España, 2.

Mallada, L. 1902. Explicación del Mapa Geológico de España. Sistemas Permiano, Triásico, Liásico y Jurásico. Memoria de la Comisión del Mapa Geológico de España, 4, 311-504.

Meister, C. 1995. Essai de correlations au Lias moyen (Sinemuriense supérieur et Carixien) entre les Pontides et les principales regions adjacentes de la Tethys occidentale et de l'Europe du nord-ouest. Géczy Jubilee Volume. Hankeniana, 1, 75-82.

Meister, C. \& Böhm, M. 1993. Australpine Liassic ammonites from the Adnet formation (Northern Calcareous Alps). Jahrbuch der Geologischen Bundesanstal, 136, 163-2011.

Meister, C. \& Friebe, J.G. 2003. Austroalpine Liassic Ammonites from Vorarlberg (Austria, Northern Calcareous Alps). Beitrage Paläontologie, 28, 9-99.

Meister, C. \& Schlögl, J. 2019. Sinemurian ammonites from Male Karpaty Mts, Western Carpathians, Slovakia. Part 3: Asteroceratinae, Eoderoceratidae, Oxynoticeratidae and rare taxa. Neues Jahrbuch fur Geologie und Paläontologie Abhandlungen, 294, 1-69; doi: 10.1127/njgpa/2019/0845.

Meister, C., Blau J., Dommergues, J.-L., Schlatter, R., Schmidt-Effing, R. \& Karsten, B. 2005. Ammonites from the Lower Jurassic (Sinemurian) of Tenango de Doria (Sierra Madre Oriental, Mexico). Part IV: Biostratigraphy, palaeobiogeography and taxonomic addendum. Revue de Paléobiologie, 24, 365-384.

Meister, C., Schirolli, P. \& Dommergues, J.-L. 2006. Sinemurian to lowermost Toarcian ammonites of the Brescian Alps
(Southern Alps, Italy): preliminary biostratigraphical framework and correlations. Volumina Jurassica, 7, 9-18.

Meléndez, G., García-Ramos, J.C., Valenzuela, M., Suárez de Centi, C. \& Aurell, M. 2002. Jurassic. Asturias. In: The Geology of Spain (eds. Gibbons, W. \& Moreno, T.). The Geological Society, London, 213-215.

Mouterde, R. \& Rocha, R.B. 1981. Atlas des fossiles caractéristiques du Lias portugais, 1- Lias inférieur. Ciências da Terra, 6, 49-76.

Neumayr, M. 1878. Über unvermittelt auftretende Cephalopodentypen im Jura Mittel-Europas. Jahrbuch der Kaiserlich-Königlichen Geologischen Reichsanstalt, 28, 37-80.

Oppel, A. 1856-1858. Die Juraformation Englands, Frankreichs und des südwestlichen Deutschlands, nach ihrn einzelnen Gliedern eingeteilt und verglichen. Ebner \& Seubert, Stuttgart.

Page, K.N. 1992. The sequence of ammonite correlated horizons in the British Sinemurian (Lower Jurassic). Newsletters on Stratigraphy, 27, 129-156.

Page, K.N. 1994. On the sequence of ammonite correlated chronostratigraphical horizons in the British Sinemurian (Lower Jurassic). In: Proceedings of the 3rd International Symposium on Jurassic Stratigraphy, Poitiers 1991. Geobios, Mémoire Spécial, 17, 369-379.

Page, K.N. 2003. The Lower Jurassic of Europe: its subdivision and correlation. Geological Survey of Denmark and Greenland Bulletin, 1, 23-59. doi: 10.34194/geusb.v1.4646

Page, N.K. 2010. Mollusca-Ammonites. In: Fossils from the Lower Lias of the Dorset Coast (eds. Lord, A.R. \& Davis, P.G.). Palaeontological Association. Field Guides to Fossils, 13, 169-261.

Pia, J. von 1914. Untersuchungen über die Gattung Oxynoticeras und einige dami zusammenhängende allgemeine Fragen. Abandlungen der Kaiserlich-königlichen geologischen Reichsanstalt, 23.

Pompeckj, J.F. 1897. Neue Ammoniten aus dem unteren Lias von Portugal. Zeitschrift der Deutschen Geologischen Gesellschaft, 49, 636-661.

Quenstedt, F.A. von 1843. Das Flözgebirge Württembergs. H. Laupp. Tübingen.

Quenstedt, F.A. von 1845. Petrefactenkunde Deutschlands. Die Cephalopoden. Ludwig Friedrich Fues. Tübingen.

Quenstedt, F.A. von 1883-1888. Die Ammoniten des Schwabischen Jura, 1-3. E. Schweizerbart'sche verlagshandlung (E. Koch), Stuttgart.

Quesada, S., Robles, S. \& Rosales, I. 2005. Depositional architecture and transgressive-regressive cycles within Liassic backstepping cabonate ramps in the BasqueCantabrian Basin, northern Spain. Journal of the Geological Society, London, 162, 531-548. doi: 10.1144/0016-764903041

Rakús, M. 1999. Some hitherto undescribed Liassic ammonites from Adnet Formation in Austria. Abhandlungen der Geologischen Bundesanstalt, 56, 319-328.

Rakús, M. \& Guex, J. 2002. Les ammonites du Jurassique inférieur et moyen de la dorsale tunisienne. Mémoire de Géologie de Lausanne, 39, 1-217. 
Reynès, P. 1879. Monographie des Ammonites. Atlas. Victor Masson. Marseilles \& Paris.

Rieth, A. 1932. Neue Funde spongeliomorpher Fucoiden aus Jura Schwabens. Neues Jahrbuch fur geologie und Paläontology Abhandlungen, 19, 257-294.

Robles, S., Pujalte, V. \& Valles, J.C. 1988. Sistemas sedimentarios del Jurásico de la parte occidental de la Cuenca Vasco-Cantábrica. Ciencias de la Tierra, 11, 1-15.

Robles, S., Quesada, S., Rosales, I., Aurell, M., Meléndez, G. \& Bádenas, B. 2002. Jurassic: Basque-Cantabrian basin. In: The Geology of Spain (eds. Gibbons, W. \& Moreno, M.T.). Geological Society, London, 215-223.

Robles, S., Quesada, S., Rosales, Aurell, M. \& García-Ramos, J.C. 2004. El jurásico marino de la Cordillera Cantábrica. In: Geología de España (ed. Vera, J.A.). SGE-IGME, Madrid, pp. 279-285.

Rodríguez-Tovar, F.J., Buatois, L.A., Piñuela, L., Mángano, M.G. \& García-Ramos, J.C. 2012. Palaeoenvironmental and functional interpretation of Rhizocorallium jenense spinosus (ichnosubsp. nov.) from the lower Jurassic of Asturias, northern Spain. Palaeogeography, Palaeoclimatology, Palaeoecology, 339-341, 114-120; doi: 10.1016/j.palaeo.2012.04.027.

Schlegelmilch, R. 1976. Die Ammoniten des Süddeutschen Lias: Ein Bestimmungsbuch für Fossiliensammler und Geologen. Gustav Fische, Stuttgart \& New York. 212 pp.

Schulz, G. 1858. Descripción Geológica de la Provincia de Oviedo. Imprenta de José González. Madrid.

Simpson, M. 1843. A Monograph of the Ammonites of the Yorkshire Lias. Simpkin, Marshall \& Co. London.

Simpson, M. 1855. The Fossils of the Yorkshire Lias; Described from Nature. Whitby. London.

Sowerby, J. 1814-1927. The Mineral Conchology of Great Britain. Meredith, London.

Spath, L.F. 1924. The ammonites of the Blue Lias. Proceedings of the Geologists' Association, 35, 186-211.

Spath, L.F. 1925-1926. Notes on Yorkshire ammonites. The Naturalist, Hull, 1925, p. 107-364; 1926, p. 45-326.
Spath, L.F. 1929. Corrections of cephalopod nomenclature. The Naturalist, Hull, 269-271.

Spath, L.F. 1946. The type of the genus Ammonites. Annals and Magazine of Natural History, 12, 490-497.

Suárez Vega, L.C. 1974. Estratigrafía del Jurásico en Asturias. Cuadernos de Geología Ibérica, 3, 1-369.

Thèvenin, A. 1907. Types du Prodrome de Paléontologie de d'Orbigny. Annales de Paléontologie, 2, 89-96.

Trueman, A.E. \& Williams, D.M. 1925. Studies in the ammonites of the family Echioceratidae. Transactions of the Royal Society of Edinburgh, 53, 699-739.

Valenzuela, M., García-Ramos, J.C., González Lastra, J.A. \& Suárez de Centi, C. 1985. Sedimentación cíclica margocalcárea de plataforma en el Lías de Asturias. Trabajos de Geología, 15, 45-52.

Valenzuela, M., García-Ramos, J.C. \& Suárez de Centi, C. 1986. The Jurassic sedimentation in Asturias (N Spain). Trabajos de Geología, 16, 121-132.

Valenzuela, M., García-Ramos, J.C. \& Suárez de Centi, C. 1989. La sedimentación en una rampa carbonatada dominada por tempestades, ensayos de correlación de ciclos y eventos de la ritmita margo-calcárea del Jurásico de Asturias. Cuadernos de Geología Ibérica, 13, 217-235.

Vegas, R., Vázquez, J.T., Olaiz, A.J. \& Medialdea, T. 2016. Tectonic model for the latest Triassic-Early Jurassic extensional event in and around the Iberian Peninsula. Geogaceta, 60, 23-26.

Wright, T. 1878-86. Monograph on the Lias ammonites of the British Islands. Monographs of the Palaeontographical Society, London.

Young, G.M. \& Bird, J. 1828. A Geological Survey of the Yorkshire Coast. Whitby, Yorkshire, England.

Zieten, C.H. von. 1830. Die Versteinerungen Württembergs. Verlag \& Lithographie der Expedition des Werkes unserer Zeit., Stuttgart. 
